\title{
CONDITION BASED MONITORING OF GAS TURBINE COMBUSTION COMPONENTS
}

\section{FINAL TECHNICAL REPORT}

Beginning October 1, 2008

Ending September 30, 2012

Nancy H Ulerich, Getnet Kidane, Christine Spiegelberg, and Nikolai Tevs

January 29,2013

Work Performed under DOE Cooperating Agreement No:

DE-NT0006833

Prepared by:

Siemens Energy, Inc. 4400 Alafaya Trail

Orlando, Florida 32826

JENTEK Sensors, Inc.

110-1 Clematis Avenue

Waltham, MA 02453-7013

K Sciences, GP LLC

26110 High Timber Pass

San Antonio, TX 78258 


\section{DISCLAIMER}

This report was prepared as an account of work sponsored by an agency of the United States Government. Neither the United States Government nor any agency thereof, nor any of their employees, makes any warranty, express or implied, or assumes any legal liability or responsibility for the accuracy, completeness, or usefulness of any information, apparatus, product, or process disclosed, or represents that its use would not infringe privately owned rights. Reference herein to any specific commercial product, process, or service by trade name, trademark, manufacturer, or otherwise does not necessarily constitute or imply its endorsement, recommendation, or favoring by the United States Government or any agency thereof. The views and opinions of authors expressed herein do not necessarily state or reflect those of the United States Government or any agency thereof. 


\section{ACKNOWLEDEMENTS}

Siemens acknowledges the Department of Energy, National Energy Technology Laboratory, for their support in this challenging project. We appreciate the reviews, comments, and suggestions that enhanced our project, as well as the funding support.

JENTEK Sensors, Inc. was responsible for the crack sensor development.

K Sciences GP, LLC was responsible for the baseline optical sensor development.

PHILTEC, Inc. developed and tested the new optical sensor for wear that Siemens conceived.

Siemens had many major contributors to this program. Getnet Kidane initiated the project and initiated the alternative optical wear sensor concept. Nicolai Tevs and Christine Spiegelberg continued sensor development, testing, validation, and analysis of data. Cliff Hatcher developed the engine validation opportunity and led the engine application design and installation effort. 


\begin{abstract}
The objective of this program is to develop sensors that allow condition based monitoring of critical combustion parts of gas turbines. Siemens teamed with innovative, small companies that were developing sensor concepts that could monitor wearing and cracking of hot turbine parts. A magnetic crack monitoring sensor concept developed by JENTEK Sensors, Inc. was evaluated in laboratory tests. Designs for engine application were evaluated. The inability to develop a robust lead wire to transmit the signal long distances resulted in a discontinuation of this concept. An optical wear sensor concept proposed by K Sciences GP, LLC was tested in proof-of concept testing. The sensor concept depended, however, on optical fiber tips wearing with the loaded part. The fiber tip wear resulted in too much optical input variability; the sensor could not provide adequate stability for measurement. Siemens developed an alternative optical wear sensor approach that used a commercial PHILTEC, Inc. optical gap sensor with an optical spacer to remove fibers from the wearing surface. The gap sensor measured the length of the wearing spacer to follow loaded part wear. This optical wear sensor was developed to a Technology Readiness Level (TRL) of 5. It was validated in lab tests and installed on a floating transition seal in an F-Class gas turbine. Laboratory tests indicate that the concept can measure wear on loaded parts at temperatures up to $800^{\circ} \mathrm{C}$ with uncertainty of $<0.3 \mathrm{~mm}$. Testing in an F-Class engine installation showed that the optical spacer wore with the wearing part. The electro-optics box located outside the engine enclosure survived the engine enclosure environment. The fiber optic cable and the optical spacer, however, both degraded after about 100 operating hours, impacting the signal analysis.
\end{abstract}


TABLE OF CONTENTS

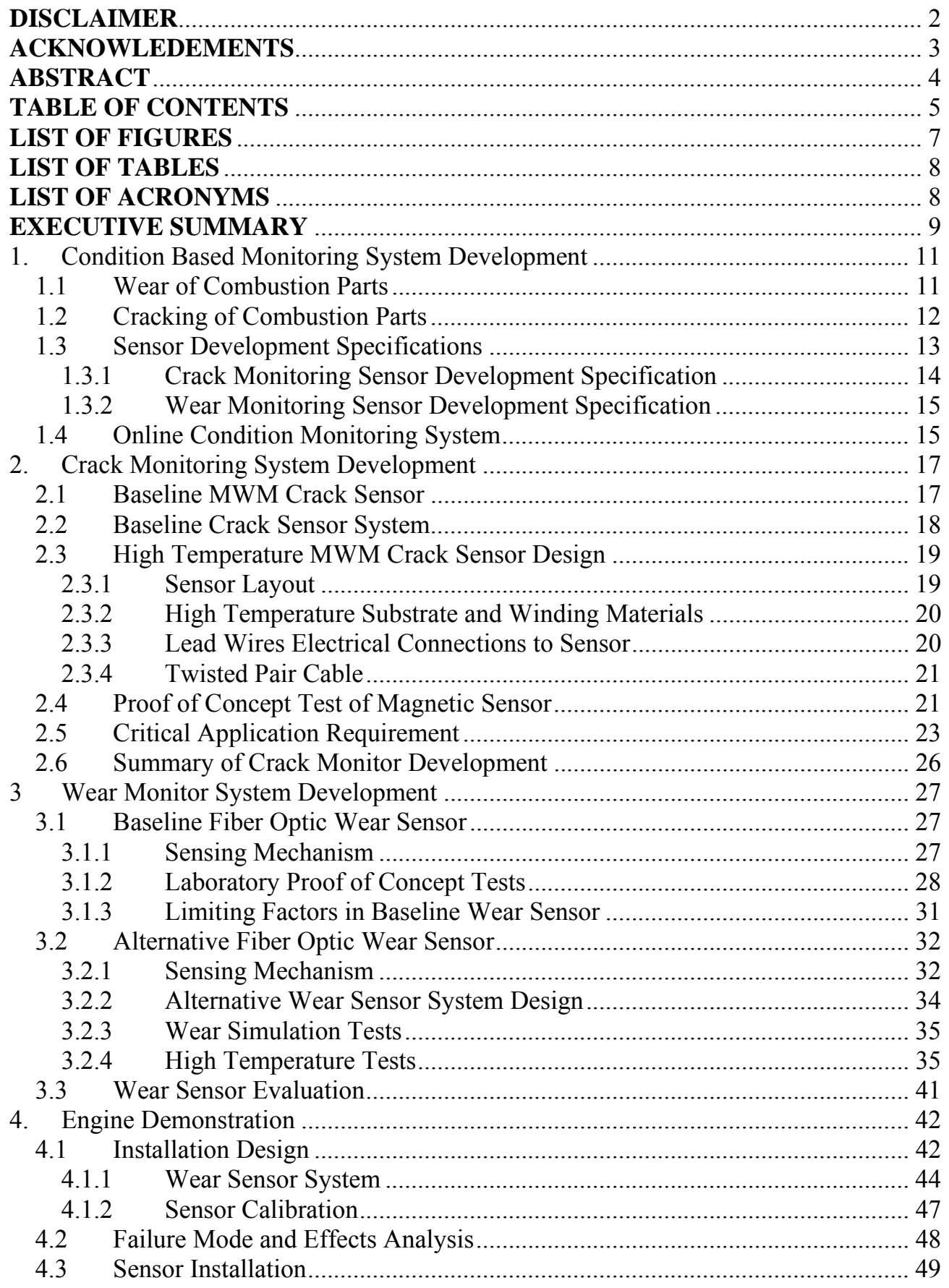


4.4 Engine Data Analysis and Discussion .......................................................... 52

4.4.1 Initial Data at Turning Gear............................................................... 52

4.4.2 Sensor Data at First Engine Startup to Full Load ..................................... 53

4.4.3 Optical Wear Sensor Signals over Six Months ......................................... 54

4.5 Post Installation Inspection and Findings ……….......................................... 55

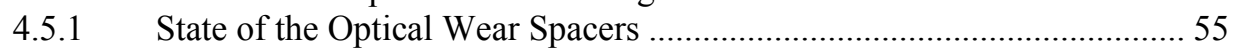

4.5.2 Wear Found on Sensors Consistent with Transition Seal Wear ............... 58

4.5.3 State of the Optical Fibers................................................................. 58

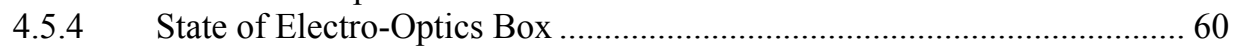

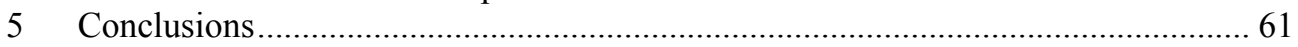




\section{LIST OF FIGURES}

Figure 1 Combustion Parts Most Prone to Wear ……....................................................... 12

Figure 2: Online Monitoring System Schematic ........................................................ 16

Figure 3: Structure and Working Principle of MWM Sensor .......................................... 18

Figure 4: JENTEK Crack Monitoring System.............................................................. 19

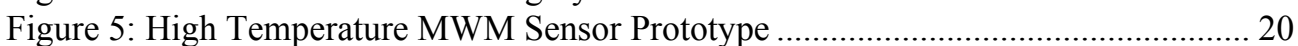

Figure 6: Room Temperature Crack Detection Test....................................................... 22

Figure 7: Temperature Crack Detection Test................................................................ 22

Figure 8: Temperature and Conductivity Relationship of Titanium Alloy....................... 23

Figure 9: Crack Monitoring System Engine Application ................................................. 23

Figure 10: High Temperature Crack Sensor: Twisted Pair Leads .................................... 25

Figure 11: Crack Detection Test with High Temperature Twisted Leads ......................... 25

Figure 12: Crack Detection Test with Twisted Pair Cable ............................................... 25

Figure 13: Baseline Fiber Optic Wear Sensor System Schematic .................................... 28

Figure 14: Fiber Transmission as a Function of Length .................................................. 28

Figure 15: Stable Optical Signal in High Temperature Tests ........................................... 29

Figure 16: Fiber Sensor Assembly in Simulated Wear Tests ........................................... 29

Figure 17: Simulated Wear Experiments Using a Lathe and a Grinder ........................... 30

Figure 18: Fiber Sensor Length as a Function of Wear Rate........................................... 30

Figure 19: Alternative Wear Sensor: Implementation of an Optical Wear Guide............. 32

Figure 20: Measurement Principle of the Fiber Optic Gap Sensor.................................... 33

Figure 21: Fiber Tip of a Reflectance Compensated PHILTEC Gap Sensor .................... 33

Figure 22: Components of the Alternative Wear Sensor System ..................................... 34

Figure 23: Wear Simulation from Grinder Experiments ............................................... 35

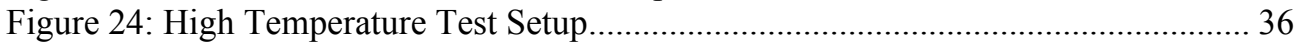

Figure 25: High Temperature Prototype ………............................................... 37

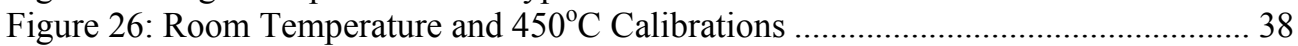

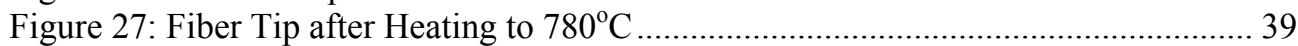

Figure 28: High Temperature Tests of the Probe Tip ...................................................... 39

Figure 29: Coated and Uncoated Fiber Bundle Heating Test .......................................... 40

Figure 30: Location of Basket 2 in Combustor Casing................................................... 42

Figure 31: Views of Vane Carrier and Installation Location of Wear Sensors................ 42

Figure 32: Schematic of Wear Sensor Installation. .......................................................... 43

Figure 33: Routing of the Wear Sensor Optical Cable ...................................................... 43

Figure 34: Layout of the Complete Wear Sensor System.................................................. 44

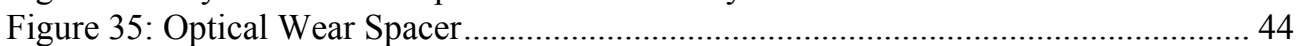

Figure 36: Fiber and Optical Wear Spacer Assembly .................................................. 45

Figure 37: Armored High Temperature Cable and Connector Facet................................ 46

Figure 38: Fiber Connector - Low Temperature Cable ..................................................... 46

Figure 39: Electro-Optics Enclosure with Cooling Fans ................................................. 47

Figure 40: Calibration with and without Wear Spacer .................................................... 47

Figure 41: Wear Sensors Installed on Upper Transition Seal............................................ 49

Figure 42: Installed Wear Spacer and Fiber Tip .............................................................. 49

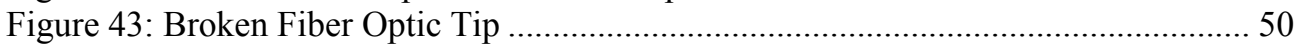


Figure 44: Row 1 Vane Carrier Showing Fiber Routing ............................................... 50

Figure 45: Fiber Crossing from Vane Carrier to Outer Turbine Casing............................ 51

Figure 46: Ratio of the Optical Channels after Installation ............................................. 52

Figure 47: Thickness Measurements at Turning Gear ................................................... 53

Figure 48: Wear Sensor Optical Signals at First Startup to Full Load ............................. 53

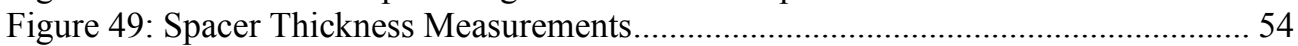

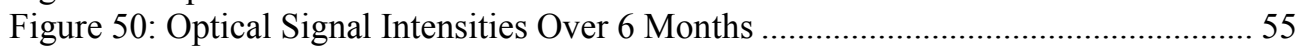

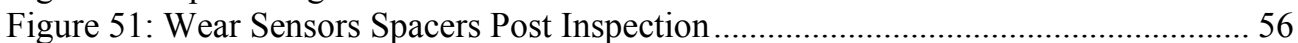

Figure 52: Wear Spacer Showing Signs of Wear .......................................................... 56

Figure 53: Wear Spacers Are Transparent Post Inspection ............................................. 57

Figure 54: Contamination on Inner Spacer Surfaces ………......................................... 57

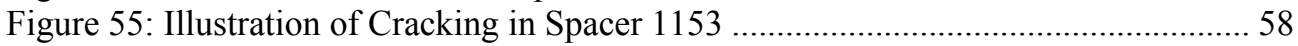

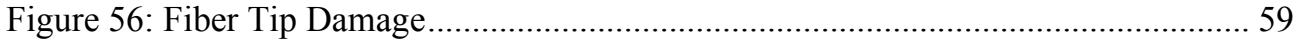

Figure 57: Photomicrographs of Fiber Tips................................................................. 59

Figure 58: Photomicrographs of Fibers Post Inspection................................................... 60

\section{LIST OF TABLES}

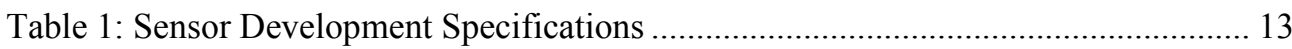

Table 2: Magnetic Sensor Proof of Concept Test Criteria............................................... 24

Table 3: Comparison of Wear Sensor Performance ……................................................ 41

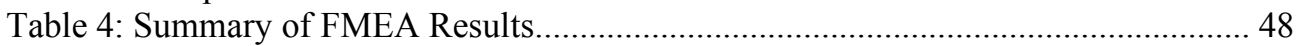

\section{LIST OF ACRONYMS}

$\begin{array}{ll}\text { DOE } & \text { Department of Energy } \\ \text { EBH } & \text { Equivalent Base Load Hours } \\ \text { FOD } & \text { Foreign Object Damage } \\ \text { HCF } & \text { High Cycle Fatigue } \\ \text { MWM } & \text { Meandering Winding Magnetometer } \\ \text { NETL } & \text { National Energy Technology Laboratories } \\ \text { REAST } & \text { Regression, Erosion, Ablation Sensor Technology } \\ \text { TBC } & \text { Thermal Barrier Coating } \\ \text { FMEA } & \text { Failure Modes and Effects Analysis } \\ \text { EMF } & \text { Electromagnetic Field } \\ \text { LED } & \text { Light Emitting Diode } \\ \text { OD } & \text { Outer Diameter }\end{array}$




\section{EXECUTIVE SUMMARY}

The reliability, availability, and maintainability of gas turbines in simple or combined cycle power plants can be impacted by degradation of components in the hot combustion section. In the absence of advanced sensor technologies for continuous real-time monitoring of these effects, power plant availability can be negatively impacted by the frequency of scheduled maintenance outages needed to inspect the hot gas path parts off line. In addition, reliability can be impacted if part failures occur. Development of advanced technologies to enable real-time condition monitoring will assist in online assessment of the condition of hot parts and allow optimization of maintenance intervals, improving power plant availability, reliability, and maintainability.

This project developed high temperature sensor technologies that can be used for direct online monitoring of combustor hardware conditions (wear and cracking) that cause part failure. Major modes of combustion hardware life degradation and failure are excessive wear at contact faces, cracks and distortions due to excessive temperature, and fatigue loads. To effectively detect and monitor these critical failure modes, this program attempted to develop two advanced online monitoring sensor technologies for gas turbine application: 1) a wear sensor to monitor wear and wear rate at wear prone areas, and 2) a sensor capable of monitoring cracking at critical locations. To accomplish these objectives, Siemens Energy teamed with three innovative small companies that developed promising sensor concepts for direct monitoring of hot component measurements, $\mathrm{K}$ Sciences GP, LLC, JENTEK Sensors, Inc., and PHILTEC, Inc.

JENTEK Sensors, Inc (JENTEK) technology is based on magnetic induction to detect material changes such as cracking. JENTEK developed a crack detection method that can detect the propagation of cracks in conducting media at low temperatures. In this program, we attempted to extend the JENTEK sensor technology to allow operation at high temperatures. This new sensor developed could detect cracks in laboratory conditions at room temperature when very short electrical leads were used to feed out the electrical signals. A problem arose, however, when longer leads, or a cable of any usable length, were attached. The low-level signals found at the sensor terminals were contaminated by loading and parasitic coupling within the cabling, and they were unstable. As a result of this and unexpected challenges to produce a robust lead wire connection method, Siemens decided to discontinue the development effort.

K Sciences GP, LLC (K Sciences) wear sensor technology is based on fiber optics. Unlike the magnetic sensors, fiber optics is not prone to signal interference in long lead cables. The K Science wear sensor concept optically measures the length of two fibers as they erode together with a wearing engine part. Laboratory tests under high temperatures and harsh accelerated wear, however, revealed a major issue with this approach. As the fibers experienced wear directly, unpredictable changes in the fiber facet quality caused erratic behavior in the optical signals. The measurement was not accurate enough for our planned applications. 
An alternative, more robust fiber optic wear sensor was developed that overcomes the limitations identified in the baseline K Sciences sensor design. The alternative method uses a fiber optic gap sensor commercialized by PHILTEC, Inc. (PHILTEC), and a transparent wear spacer that erodes together with the wearing part and protects the fiber optic facets. Simulated high-speed wear tests demonstrated a large improvement in the accuracy and repeatability of this sensor, and operating temperatures of $>800^{\circ} \mathrm{C}$ were demonstrated in laboratory tests. Based on these results, we developed a complete high temperature sensor system, and installed the system in an operating gas turbine. The floating exit seal of the combustor section of an F-Class engine was selected to validate the sensor. This sensor was developed to a Technology Readiness Level (TRL) of 5. Two sensors were successfully installed in an F-Class engine, and we were able to monitor the response of these wear sensors over a period of about six months of engine installation. 


\section{Condition Based Monitoring System Development}

Hot section combustion part life limiting locations and major failure modes vary from engine to engine based on the type of combustion system, operating conditions, part material, and part design characteristics. The general failure modes and failure driving mechanisms of hot section combustion parts are, however, similar. Combustion parts (i.e., basket, transition, pilot nozzle, and fuel support housing) were evaluated to study the characteristics of wear and crack damage, and define desired monitoring needs. Service data analysis and design models of these parts identified the following potential life limiting failure mechanisms of hot section combustion parts:

- wear damage at loosely connected interface joints

- cracking and crack-induced damage

- thermal barrier coating loss

- surface erosion

- oxidation and corrosion damage

- creep damage

- foreign object damage (impact damage from objects in the flow path)

Wear and crack damage are the most probable of these life-limiting failure mechanisms.

\subsection{Wear of Combustion Parts}

Some high temperature combustion parts assembly interfaces are designed with loosely loaded joints for the purposes of accommodating thermal growth fluctuations during operation and dampening vibration loads. Excessive relative motion of the parts at these interface joints from vibration motion is the major driving factor for wear damage. Unless the joints are highly loaded and locked together to eliminate motion, wear coatings or wear resistance materials are often necessary to obtain longer service life. Appropriate wear resistant coatings and material selection usually slows the wear rate, but it may not completely stop the wear. Sliding motion created from thermal cyclic growth at the sliding interface is relatively small compared to motion created by vibration. Thermal cyclic growth of mating surfaces, therefore, will not normally cause excessive wear.

Critical locations susceptible to wear in the combustion section are shown in Figure 1:

- combustion basket and transition assembly interface

- combustion basket swirler bore and fuel nozzle assembly interface

- transition and stage 1 vane assembly interface 


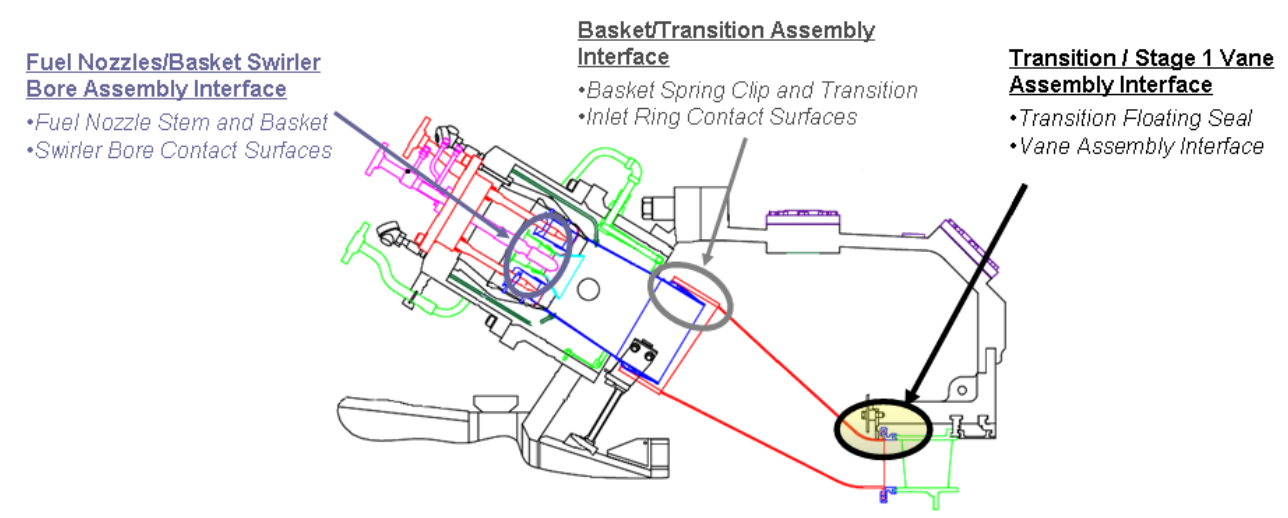

Figure 1 Combustion Parts Most Prone to Wear

Wear prone critical locations of combustion parts require regular inspection during maintenance outages. Parts get scrapped or repaired during inspection depending on the extent of wear found compared to allowable limits specified in service bulletins.

\subsection{Cracking of Combustion Parts}

Thermal fatigue-induced cracking is also a common damage mechanism for hot section combustion parts. The inside surfaces of the combustion parts are exposed to the high temperature of the combustion gas, typically above $1000^{\circ} \mathrm{C}\left(1832^{\circ} \mathrm{F}\right)$ in modern gas turbines, and the other side are cooled by the compressor discharge air that runs typically around $400^{\circ} \mathrm{C}$ to $500^{\circ} \mathrm{C}\left(752^{\circ} \mathrm{F}\right.$ to $\left.932^{\circ} \mathrm{F}\right)$. This high temperature gradient across the parts is responsible for thermal fatigue loads during transient and steady state operation cycles. Crack-induced failures in combustion hardware cannot be eliminated due to the nature of the operating environment, but the impact can be mitigated by judicious design and operation.

Another source of crack initiation on combustion hardware is high cycle fatigue (HCF) from combustion dynamics and component vibration excitation. Accelerated crack growth and subsequent parts failure will result unless the excitation driver is removed. The impact of HCF induced fatigue cracks can be minimized by proper component design and control of the operation parameters contributing to the excessive vibration.

All other damage modes that weaken or degrade part's material strength ultimately trigger cracking at the weakest point. In general, no crack is allowed on any critical combustion part. Cracking can initiate anywhere on the part where there is high cyclic stress and temperature or where the part strength is compromised by some kind of material degradation mechanisms (e.g., oxidation, corrosion, creep). Detection of crack initiation and crack growth is, therefore, an effective way of assessing parts condition online. 


\subsection{Sensor Development Specifications}

To clearly understand the nature of wear and crack monitoring needed in combustion parts, the Siemens project team identified life limiting critical locations, determined failure-driving factors, and defined the operating environment at the critical part locations. Using this information, we developed sensor design requirements presented in Table 1.

Table 1: Sensor Development Specifications

\begin{tabular}{|c|c|c|}
\hline \multicolumn{3}{|c|}{ CRACK MONITOR } \\
\hline Requirements & Target & Comments \\
\hline $\begin{array}{l}\text { Sensor Maximum Operating } \\
\text { Temperature }\end{array}$ & $1000^{\circ} \mathrm{C}\left(1832^{\circ} \mathrm{F}\right)$ & $\begin{array}{l}\text { High target for a new sensor } \\
\text { development }\end{array}$ \\
\hline $\begin{array}{l}\text { Transmission Cable Operating } \\
\text { Temperature }\end{array}$ & $500^{\circ} \mathrm{C}\left(932^{\circ} \mathrm{F}\right)$ & $\begin{array}{l}\text { Transmission cable from sensor } \\
\text { location to outside engine casing }\end{array}$ \\
\hline Crack Detection Resolution & $\begin{array}{l}\text { Minimum of } 0.50 \mathrm{~mm} \\
\text { length by } 0.25 \mathrm{~mm} \text { depth }\end{array}$ & \\
\hline $\begin{array}{l}\text { Crack Growth Monitoring } \\
\text { Range (maximum length) }\end{array}$ & 0 to $30 \mathrm{~mm}$ & Prototype sensor target \\
\hline $\begin{array}{l}\text { Temperature Measurement } \\
\text { Accuracy }\end{array}$ & $+/-15^{\circ} \mathrm{C}\left(27^{\circ} \mathrm{F}\right)$ & $\begin{array}{l}\text { Secondary objective for dual use } \\
\text { (temperature and crack monitor) }\end{array}$ \\
\hline Sensor System Operating Life & $\begin{array}{l}\text { Minimum } 2000 \text { hours for } \\
\text { prototype sensor }\end{array}$ & $\begin{array}{l}\text { Goal is design life of combustion } \\
\text { parts inspection interval }\end{array}$ \\
\hline \multicolumn{3}{|c|}{ WEAR MONITOR } \\
\hline Requirements & Target & Comments \\
\hline $\begin{array}{l}\text { Sensor Maximum Operating } \\
\text { Temperature }\end{array}$ & $1000^{\circ} \mathrm{C}\left(1832^{\circ} \mathrm{F}\right)$ & $\begin{array}{l}\text { Very high target for a new sensor } \\
\text { development }\end{array}$ \\
\hline $\begin{array}{l}\text { Fiber Optic Transmission } \\
\text { Cable Operating Temperature }\end{array}$ & $500^{\circ} \mathrm{C}\left(932^{\circ} \mathrm{F}\right)$ & $\begin{array}{l}\text { Transmission cable from sensor } \\
\text { location to outside engine casing }\end{array}$ \\
\hline Wear Measurement Resolution & $+/-0.025 \mathrm{~mm}(0.001 \mathrm{in})$ & $\begin{array}{l}\text { Very tight target, } 25 \text { microns is } \\
\text { within surface roughness limit of } \\
\text { machined surfaces }\end{array}$ \\
\hline Wear Measurement Range & 0 to $10 \mathrm{~mm}$ & Prototype sensor target \\
\hline Sensor System Operating Life & $\begin{array}{l}\text { Minimum } 2000 \text { hours for } \\
\text { prototype sensor }\end{array}$ & $\begin{array}{l}\text { Goal is design life of combustion } \\
\text { parts inspection interval }\end{array}$ \\
\hline $\begin{array}{l}\text { Sensor Wear Rate } \\
\text { Characteristics }\end{array}$ & $\begin{array}{l}\text { Sensor probe tip shall } \\
\text { wear at the same rate as } \\
\text { the wearing parts. }\end{array}$ & $\begin{array}{l}\text { Sensor measures wear by } \\
\text { determining the amount of } \\
\text { material worn from the sensor tip }\end{array}$ \\
\hline
\end{tabular}




\subsubsection{Crack Monitoring Sensor Development Specification}

The following multifunction magnetic system development specifications were developed to meet combustion parts crack monitoring needs, operating conditions, and the DOE high temperature sensor development goals.

Sensor Crack Detection Resolution and Accuracy: No crack damage is allowed in most critical locations of combustion parts. In order to detect crack initiation and monitor crack growth effectively, the multifunction magnetic sensor shall, therefore, have crack detection resolution and accuracy of as small as $0.50 \mathrm{~mm}(0.02$ inch $)$ in length and $0.25 \mathrm{~mm}(0.01 \mathrm{inch})$ deep, and it will be capable of monitoring the crack growth for up to $30 \mathrm{~mm}$ (1.18 inch) or more in length.

Sensor Temperature Measurement Accuracy: The magnetic sensor shall have monitor surface temperature with measurement accuracy of $+/-15^{\circ} \mathrm{C}\left(+/-27^{\circ} \mathrm{F}\right)$. The primary goal of the multifunction magnetic sensor is to monitor crack damage on high temperature combustion components. The sensor's temperature monitoring capability is, therefore, of secondary importance.

Magnetic Sensor Operating Temperature: The magnetic sensor shall have an operating temperature of $\geq 1000^{\circ} \mathrm{C}\left(1832^{\circ} \mathrm{F}\right)$ of continuous exposure during online monitoring application.

Transmission Cable Operating Temperature: The sensor signal transmission and power supply wires used from the sensor location to the outside of the engine casing shall have an operating temperature of $500^{\circ} \mathrm{C}\left(932^{\circ} \mathrm{F}\right)$.

Sensor System Operating Life: The desired operating life of the sensor system (magnetic sensor, packaging, transmission wire, attachments, and in-between connections) is to last more than a single maintenance outage interval of the combustion section. For the prototype system demonstration test application, the sensor system shall have a minimum of 2000 hours life while operating continuously in the harsh operating environment of the combustion section.

Sensor System Electronics Specification: Existing JENTEK's signal processing electronics system will be used for this application. No design modification of the system is expected.

Software: The online monitoring result display software shall be user friendly and needs to show measured crack length and depth, trend of crack growth, and allowable limits clearly. It also needs to show the measured surface temperature value. 


\subsubsection{Wear Monitoring Sensor Development Specification}

The following wear sensor system development specifications were developed to meet critical combustion parts wear monitoring needs, operating conditions, and DOE high temperature sensor development goals.

Wear Sensor Measurement Resolution and Accuracy: The wear sensor shall have both measurement resolution and accuracy of up to $+/-0.025 \mathrm{~mm}(0.001 \mathrm{inch})$ to detect the small incremental wear growth of combustion parts.

Wear Sensor Operating Temperature: The wear sensor probe shall have an operating temperature of $\geq 1000^{\circ} \mathrm{C}\left(1832^{\circ} \mathrm{F}\right)$ of continuous exposure during online engine monitoring application.

Transmission Cable Operating Temperature: The fiber optic cable used to transmit the measured signal from the sensor location to the outside of the engine casing shall have an operating temperature of $500^{\circ} \mathrm{C}\left(932^{\circ} \mathrm{F}\right)$.

Sensor System Operating Life: The desired operating life of the sensor system (sensor, packaging, transmission cable, attachments, and in-between connections) is to last more than a single maintenance outage interval of the combustion section. For the prototype system demonstration test application, the sensor system shall have a minimum of 2000 hours life while operating continuously in the harsh operating environment of the combustion section.

Sensor Probe Wear Characteristics: The wear probe tip, which is in contact with the wearing surface, shall have compatible wear characteristics as the wearing layers so that the tip erodes at the same rate as the wearing surface.

Sensor System Electronics Specification: The electronics system consists of the optical light detector and the associated signal processing electronics. The system must have acceptable level of optical light detection efficiency to convert the optical power to electrical signal that is required to detect and measure the small incremental wear progression.

Software: The online monitoring result display software shall be user friendly and needs to show measured wear depth amount, trend of wear progression, and allowable limits clearly.

\subsection{Online Condition Monitoring System}

We envision that the wear and crack sensors will form a sensor network with the existing engine supervisory instrumentation to monitor and evaluate condition of parts in real time. 
Direct monitoring of the wear and cracking online enable accurate assessment of the parts condition.

Figure 2 illustrates a typical sensor network for online condition monitoring of combustion parts. Signals generated from the individual wear and crack sensors are routed to different signal pre-processing electronics. The processed signals are then connected to an integrated computer for further data processing, display, tracking, and data storage.

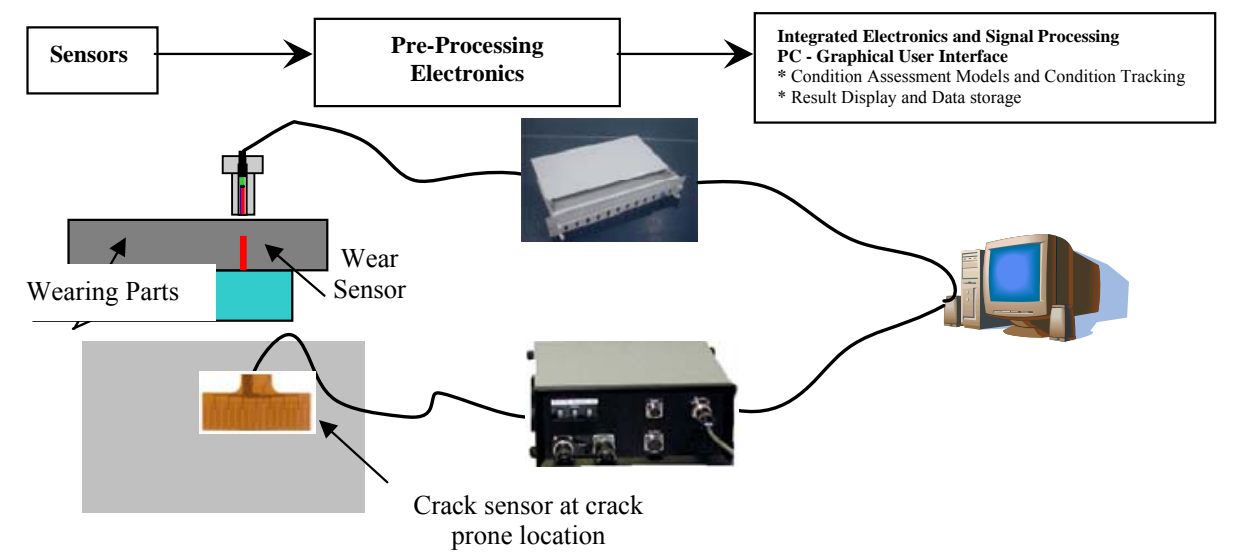

Figure 2: Online Monitoring System Schematic

To effectively use wear and crack sensor data, we developed condition monitoring models and a maintenance interval optimization approach for combustion components. The developed models use wear and crack sensor input, together with the basic engine supervisory sensor input, to assess the condition of combustion components online and give early warnings of any imminent failure.

We performed a thorough examination of service data on damage history of combustion parts collected during power plant outages. Part condition assessment models were developed using information from Siemens part inspection criteria and service requirements, design life models, and statistical analysis of field service data. These models can be used, together with engine supervisory sensors, to interpret measured wear and crack sensor data and assess the condition of selected combustion components. In addition, the models provide the information required to optimize maintenance outage intervals. 


\section{Crack Monitoring System Development}

JENTEK Sensors, Inc. (JENTEK) developed a crack detection technology based on meandering winding magnetometers (MWM) and current measurements. A MWM sensor consists of an insulating substrate on which specially arranged conducting windings are imprinted. The typical geometry comprises one drive winding and multiple sensing windings. The MWM sensor is placed in close vicinity to the material under test. When an alternating current is applied to the drive winding, it creates a magnetic field that penetrates the material; and induces a current in the material. The induced current is influenced by its electrical properties (i.e., magnetic permeability and electrical conductivity). For conducting materials, the induced current pattern follows the winding pattern of the primary drive. When a crack or corrosion damage alters the flow of these currents, the inductive sensing coils of the MWM-Array sense an absolute magnetic field that is altered locally by the presence of the crack or other damage. A single element sensor has multiple secondary windings or sensing elements connected so that a single output voltage is measured. The absolute impedance (sensing element voltage/drive winding current) is measured using a JENTEK impedance instrument. The impedance is then used as an input to a multivariate inverse method to determine one or more absolute material property values (electrical conductivity, magnetic permeability, proximity, or layer thickness) at the location of the sensing element on the test specimen or component. Databases or measurement grids of sensor responses are used to convert impedance data into two or more unknown property estimates at each sensing element.

JENTEK developed a range of integrated magnetic sensor systems for aerospace, defense, automotive, energy, manufacturing and consumer products industries for non-destructive testing, materials characterization, and damage monitoring. At the beginning of the project, these systems were limited to operating temperatures of 4.5 to $32^{\circ} \mathrm{C}\left(0\right.$ to $\left.90^{\circ} \mathrm{F}\right)$.

The goal of this project was to adapt the MWM technology for high temperature, realtime monitoring of hot section combustion parts with operating temperatures up to $1000^{\circ} \mathrm{C}\left(1832^{\circ} \mathrm{F}\right)$, allowing crack and temperature monitoring of combustion parts. Major system upgrades and design improvements with respect to sensor layout, attachment methods, signal routing, and condition assessment algorithms specific to combustion parts were planned.

A summary of the results obtained in this program is provided below.

\subsection{Baseline MWM Crack Sensor}

Figure 3 shows an example of a baseline senor element together with a sketch of the working principle. The current generation of single channel MWM sensors, shown in Figure 3, is based on interdigitated drive loops printed on a thin and flexible Kapton substrate. The drive winding is driven by a sinusoidal time varying signal with known amplitude. 

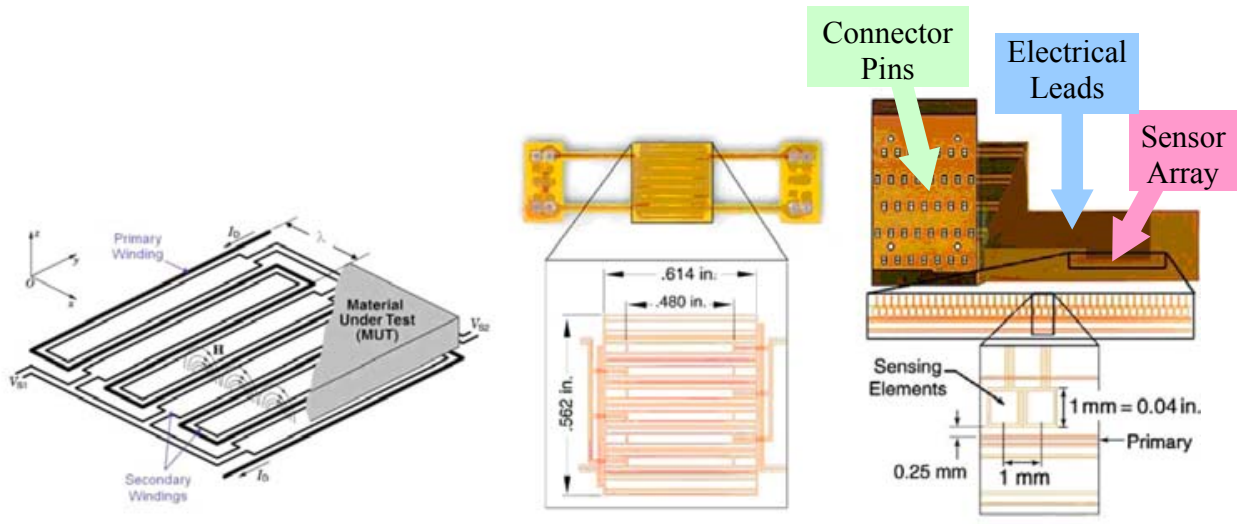

Figure 3: Structure and Working Principle of MWM Sensor

In a typical geometry, the sensing windings are placed on either side of the longer segments of the primary windings. In an MWM-Array, multiple small sensing elements (e.g., $1 \mathrm{~mm}$ by $1 \mathrm{~mm}$ square) are located between longer segments of a single rectangular shape drive winding shown in Figure 3. To minimize the effect of stray inductive and capacitive coupling to the sensor leads, the signals are routed out of the sensor area by special flux cancelling leads that are part of the flex circuit. This technology allows longer leads to be used, permitting the conduction leads to be spread out to the connection leads of a conventional pin type connector, and reducing cross talk problems encountered in closely spaced connector schemes.

The baseline JENTEK MWM-Array sensors described above are capable to operate at temperature up to $270^{\circ} \mathrm{C}\left(820^{\circ} \mathrm{F}\right)$. To extend the sensor operating temperature to $1000^{\circ} \mathrm{C}$ $\left(1832^{\circ} \mathrm{F}\right)$, the substrate as well as the winding material and the electrical interconnects, need to be changed.

\subsection{Baseline Crack Sensor System}

A typical crack monitoring system consists of the MWM-Array Sensor, with flux cancelling leads that are connected to a signal-conditioning unit, data acquisition boards in the measurement instrument, and a computer with signal processing software and graphical user interface. Figure 4 shows these system components. JENTEK developed a compact signal-conditioning unit that can accommodate a large number of channels, and it can easily be connected to the flex circuit sensor. Signal conditioning involves amplification, buffering, and filtering. It is important to use short, preferably fluxcancelling leads because the low-level signals found at the sensor terminals can easily be contaminated by loading and parasitic coupling within the cabling to the instrument. A longer cable can then be used to connect to the impedance measurement unit, which is also used to power the signal conditioning electronics and generate the drive signals. 


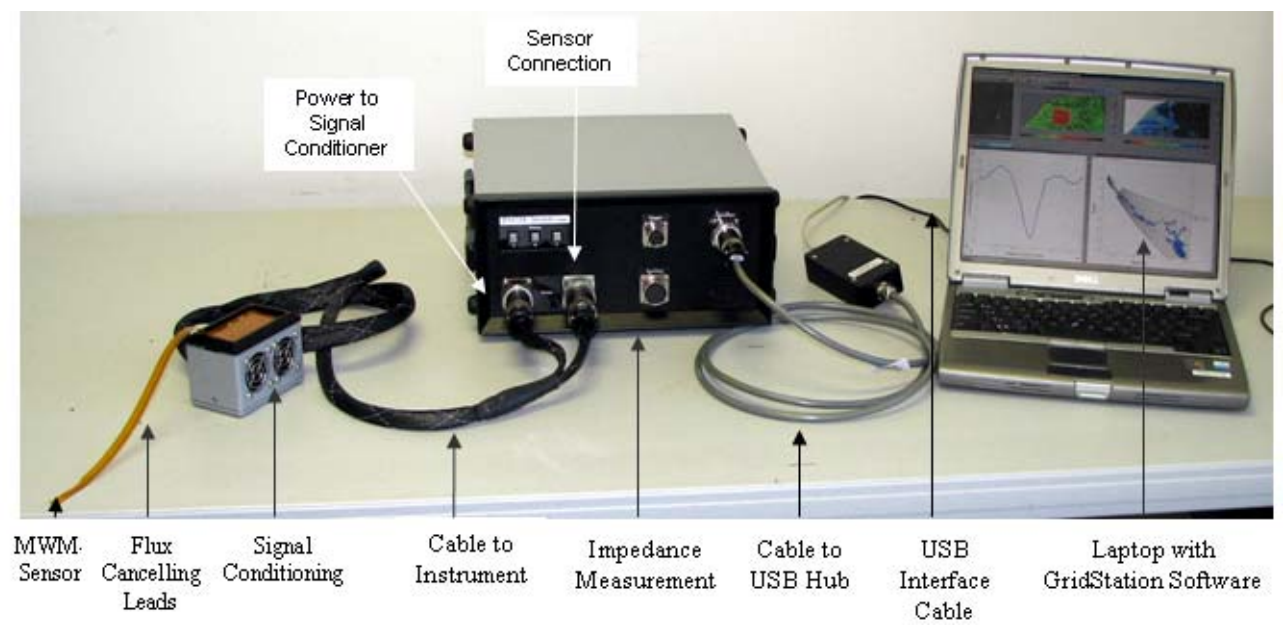

Figure 4: JENTEK Crack Monitoring System

The GridStation ${ }^{\circledR}$ Software uses Measurement Grids, Lattices \& Hyperlattices to convert impedance measurements into electrical properties and layer thicknesses, generating images used to detect defects and assess condition. Grids, Lattices and Hyperlattices are two, three, and four or higher dimension pre-computed databases, respectively. These databases are generated off-line using physics-based models of the sensor and multilayered material under test, and stored for use by the GridStation software.

Basic features and specifications are:

- Frequency range: $100 \mathrm{~Hz}$ to $15 \mathrm{MHz}$

- Power Requirements: Standard "wall” power, i.e. $120 / 240$ V, 50/60Hz

- Serial Communication: RS-422 or USB (with adapter cable)

- Operating Temp: $40-90^{\circ} \mathrm{F}$

- Maximum serial cable length to host system: $>100 \mathrm{ft}$.

Limited modification work was planned to modify the current GridStation software. The planned software upgrades included modifying the measurement grid database using lab calibration of the high temperature sensor on a representative combustion part material, modify the "plug-in" and play module, and develop a method to export the measurements in a format appropriate for online monitoring application.

\subsection{High Temperature MWM Crack Sensor Design}

\subsubsection{Sensor Layout}

Two possible layouts for the high temperature MWM-Array prototype sensor were developed. In the first option, both the sensor and driving windings are printed on the 
same side of the substrate. In the second option, the windings are printed on opposite sides of the sensor substrate. The first option was used to fabricate an initial batch of sensors used in the proof-of-concept tests. Windings were printed on the substrate surface using photo-patterned thick film and screen-printing fabrication methods. Two different vendors were used. Laboratory testing of the one-sided winding magnetic sensor identified the presence of signal interference in the measured data due to the coupling of the driver winding to the sensing elements. It was, therefore, decided to fabricate the sensor using the second option (i.e., sensor and driver windings on opposite sides of substrate) with improved winding circuits.

\subsubsection{High Temperature Substrate and Winding Materials}

A review of the various material properties, as well as the compatibility of the substrate and winding materials, needed to survive the temperature requirements and to accommodate the thermal strains was performed. Suitable candidate materials were identified. Issues with the material applications were reviewed and manufacturing options proposed.

Various high temperature metals were reviewed for sensor winding fabrication and a solution was developed.

\subsubsection{Lead Wires Electrical Connections to Sensor}

The lead wires connecting the MWM Array to the conditioning unit and their attachment to the array are critical elements of the sensor. One complication in designing and fabricating the arrays is the need to bring out numerous leads from the sensing elements. The connections need to be sturdy and robust and, at the same time, guarantee signal integrity comparable to the flex circuit type flux cancelling lead solution.

JENTEK investigated various techniques of attaching lead wires to the sensor winding terminals. Figure 5 shows the MWM prototype with short wires used for the laboratory proof-of-concept tests.

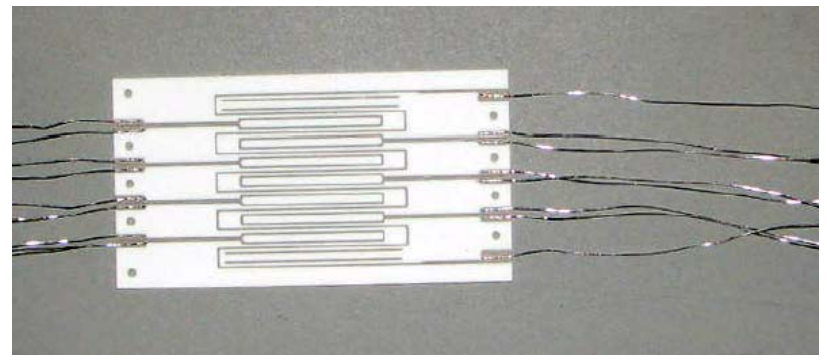

Figure 5: High Temperature MWM Sensor Prototype 


\subsubsection{Twisted Pair Cable}

It is important to note that the MWM array and the interconnecting cable both contribute to the inductance, capacitance, and resistance of the impedance bridge circuit. The circuit cannot distinguish between sensor and cable induced impedance changes. Short leads and signal conditioning are standard ways to minimize this problem, but they cannot be used in this engine application that requires a single long $(\sim 7 \mathrm{~m})$ cable to feed the sensor signals into the conditioning unit outside the turbine casing.

It is clear that any such cable has to be very well shielded and the measurements channels isolated. For this application, a twisted pair arrangement was selected over a coaxial cable because of its capability to suppress external electromagnetic field (EMF) interferences. A twisted pair essentially wraps itself in its own magnetic field, and cancels out external interference.

JENTEK developed a concept to produce the twisted pair cable and conducted many fabrication trials. The twisted pair's susceptibility to electromagnetic interference greatly depends on the pair twisting schemes staying intact during the installation and packaging. As a result, twisted pair cables usually require some pulling tension to be present at all times to prevent wires separation. This extra work to make and package the twisted pair put significant strain to the twisted pair cable and leads wire connection strength. As a result, all trials were unsuccessful due to lead wire failure close to the welding joint at the sensor pad during the cable packaging process.

\subsection{Proof of Concept Test of Magnetic Sensor}

Crack detection demonstration of the prototype sensor was conducted at room temperature using a notched specimen. In lieu of a long high temperature cable, interface boards were attached to the short temperature tolerant leads and twisted pair copper cables used to connect to the signal-conditioning unit. To simulate crack propagation, the specimen was moved with respect to the sensor so that the notch would sequentially reach channels of increasing order. A photograph of this experimental setup is shown in Figure 6 . The crack can clearly be detected and the effective conductivity measured by each channel changes by about $20-30 \%$ as the notch reaches the channel. The data also indicate the presence of parasitic electromagnetic field coupling which manifests itself in alternating polarity changes and a decreases in magnitude as the notch reaches sequential channels. 

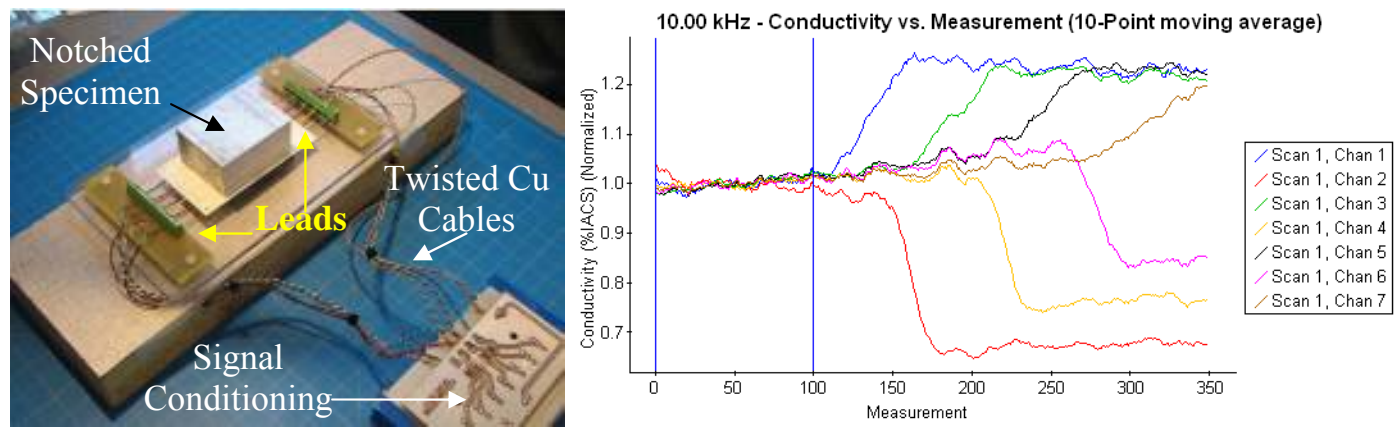

Figure 6: Room Temperature Crack Detection Test

Figure 7 shows the room temperature crack detection test conducted on another Inconel617 alloy notched specimen. It is not clear why in this test the phase changes observed in the above aluminum specimen were not repeated. Nevertheless, the signal-to-noise ratio is high, so the crack can be detected with high fidelity.

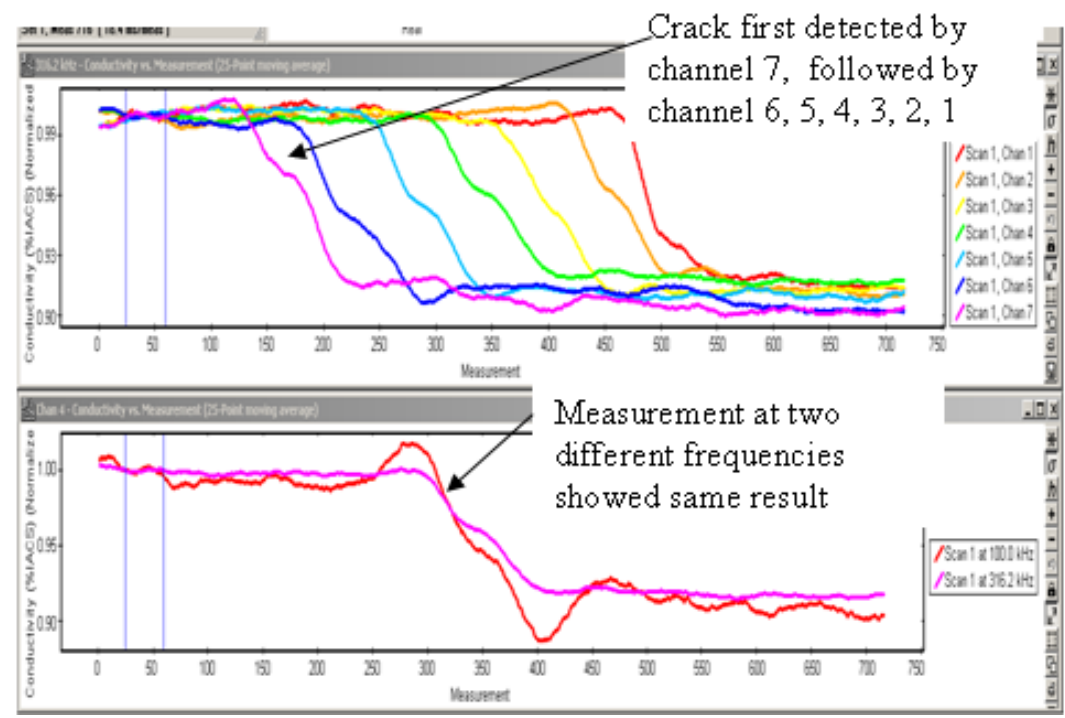

Figure 7: Temperature Crack Detection Test

Temperature measurement using the magnetic sensor is accomplished at the data processing stage by interpolating the measured sensor output (current conductivity) to the predetermined calibration database stored in the GridStation software (sensor response at various temperatures). Figure 8 shows the typical relationship of the measured conductivity to a temperature increase. 


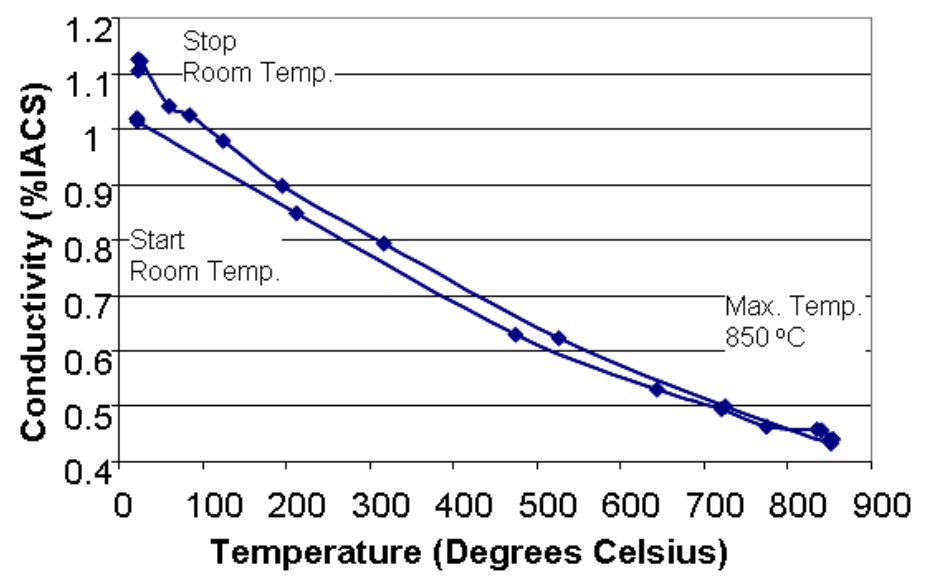

Figure 8: Temperature and Conductivity Relationship of Titanium Alloy

JENTEK also conducted a series of high temperature tests by placing the sensors in a furnace operating at temperatures up to $850^{\circ} \mathrm{C}$ while monitoring the change in resistance of the sensing wires. In all the tests, the sensing elements resistance remained stable and all the responses were as expected. Table 2 summarizes proof-of-concept test targets and demonstrated results obtained.

\subsection{Critical Application Requirement}

A functional sensor system for any practical purpose in an engine application requires a relatively long transmission cable to feed the signals out of the combustor casing to the signal conditioning or impedance measurement instrument. The requirements on such a cable are extremely demanding. The cable has to be robust and able to withstand the harsh environment in an engine while, at the same time, it has to transmit very small signals at high frequency and with high fidelity. For the selected application on a transition, the cable will experience temperatures of almost $1000^{\circ} \mathrm{C}$ for the first $1.5 \mathrm{~m}$. The cable length required to feed the signal out of the cooled engine casing where temperatures still reach $500^{\circ} \mathrm{C}$ is about 4 meters as illustrated in Figure 9.

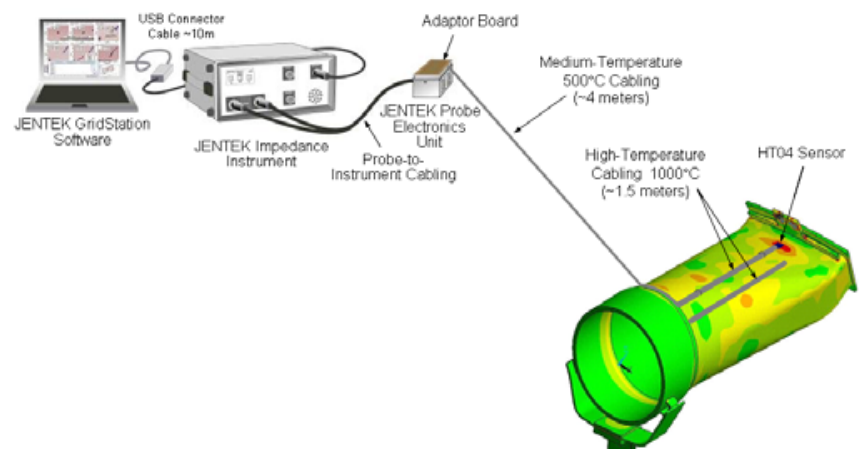

Figure 9: Crack Monitoring System Engine Application 
Table 2: Magnetic Sensor Proof of Concept Test Criteria

\begin{tabular}{|l|l|l|l|l|}
\hline No. & $\begin{array}{l}\text { Laboratory Proof of } \\
\text { Concept Test Criteria }\end{array}$ & Target & Test and Results & Pass/Fail \\
\hline 1 & $\begin{array}{l}\text { Demonstrate the sensor can } \\
\text { provide stable, repeatable, } \\
\text { and reliable signals when } \\
\text { used at room temperature and } \\
\text { high temperature } \\
\text { environment. }\end{array}$ & $\begin{array}{l}\text { Sensor } \\
\text { winding wires } \\
\text { resistance } \\
\text { change shall } \\
\text { be }<5 \%\end{array}$ & $\begin{array}{l}\text { * Conducted experiments to } \\
\text { evaluate the change in resistance } \\
\text { of the sensor wires before and } \\
\text { after heating at } 850^{\circ} \text { C for } 8 \text { hours. } \\
* \text { Result: the difference in } \\
\text { resistance of the wires before and } \\
\text { after the test is less than 5\%, and } \\
\text { is within acceptable range of } \\
\text { system functionality. }\end{array}$ & Passed \\
\hline 2 & $\begin{array}{l}\text { Demonstrate the sensor can } \\
\text { detect crack and monitor } \\
\text { simulated crack growth at } \\
\text { room temperature (slide the } \\
\text { sensor over the crack } \\
\text { sample). }\end{array}$ & $\begin{array}{l}\text { Detect crack } \\
\text { on a notched } \\
\text { specimen }\end{array}$ & $\begin{array}{l}\text { * Conducted crack growth } \\
\text { simulation test by sliding a } \\
\text { notched specimen over the high } \\
\text { temperature sensor. } \\
* \text { Result: The sensing elements of } \\
\text { the 7-channels high temperature } \\
\text { sensor able to detect the crack as } \\
\text { it passed over each sensing }\end{array}$ & Passed \\
\hline element.
\end{tabular}

As shown in previous sections, a method was developed and demonstrated to connect short, temperature-tolerant lead wires to the sensor input/output terminals. The lead wires need, however, to be connected to a long transmission cable that combines eight pairs of twisted lead wires in a single shielded cable. The development of this transmission cable and its connections presented a major technical challenge. Lead wire breaking at the junction near the welded terminal pads could not be avoided. Figure 10 illustrates the weak spot of the electrical connections. 


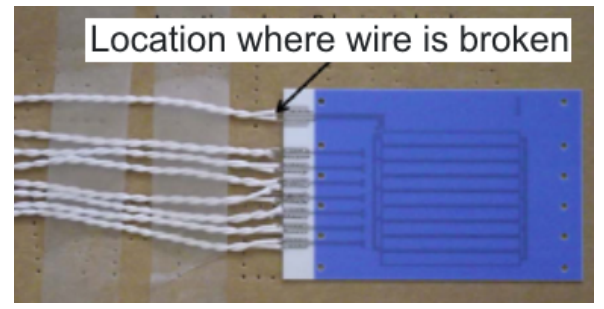

Figure 10: High Temperature Crack Sensor: Twisted Pair Leads

JENTEK pursued several routes to overcome this problem and considered alternate cable materials, as well as different attachment techniques. This attachment problem, however, was not solved. Figure 11 shows the setup used in this room temperature experiment.

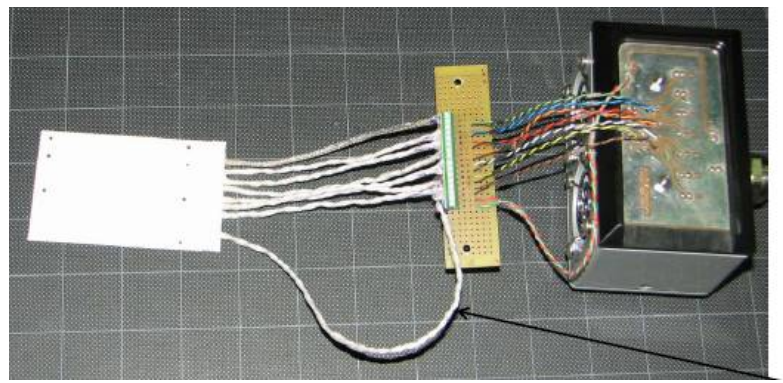

Figure 11: Crack Detection Test with High Temperature Twisted Leads

Figure 12 compares these test results with the expected outcome obtained earlier with short low temperature cables.

\section{Room Temperature Crack Detection Experiments}

$10 \mathrm{~cm}$ High Temperature Twisted Cable

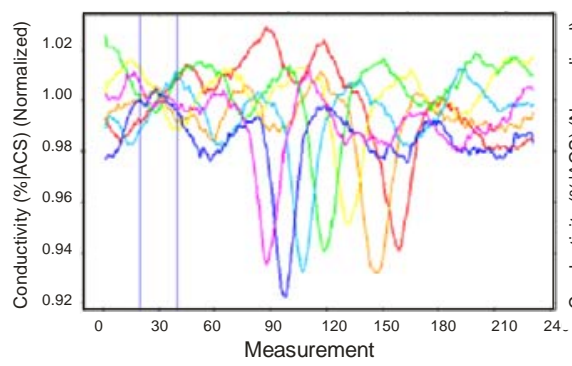

$5 \mathrm{~cm}$ Straight Leads $+20 \mathrm{~cm}$ Standard Twisted Copper

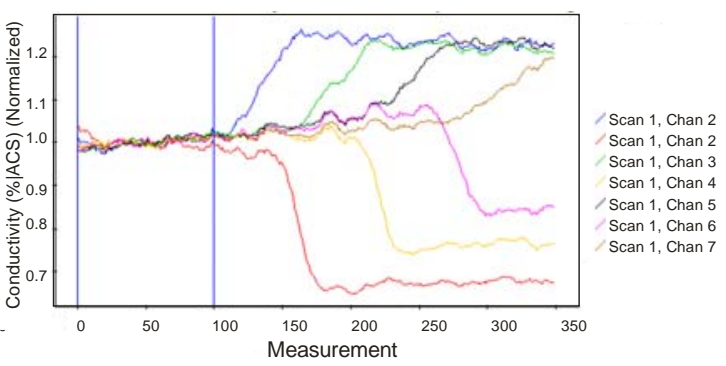

Figure 12: Crack Detection Test with Twisted Pair Cable

Even with a short $(\sim 10 \mathrm{~cm})$ electrical cable, the electrical signals were not stable and they could not be correlated with the crack propagation. Significant electromagnetic coupling between wires in the cable produced random changes in recorded voltages Although care was taken to use twisted wires and external shielding, spurious signals were larger than 
the small signal created in the sensor coil. All attempts to produce longer cables were unsuccessful. If not solved with an extremely sophisticated cable design, this problem puts a serious limitation on the use of this high temperature sensor in out targeted gas turbine applications.

\subsection{Summary of Crack Monitor Development}

JENTEK completed the design and fabrication of the sensor and demonstrated its capability to operate in a high temperature environment to detect cracks and temperature in the laboratory proof-of-concept tests. These tests, however, were conducted by attaching short lead wires to the sensing element terminals. For more than one year, project activities focused on developing a reliable lead wire connection method and cable packaging. This was unsuccessful. The technical issues associated with the cable packaging and interconnects resulted in significant delays to prototype tests. As a result of unexpected challenges to produce a robust lead wire connection method and a twisted pair cable, Siemens decided to discontinue the development effort. 


\section{Wear Monitor System Development}

The high temperature optical wear sensor developed under this project is an intensitybased fiber optic sensor able to monitor wear progression as a sensor tip wears together with the wearing surface. As part of our development and risk mitigation plan, two optical technologies with different operating principles were developed and evaluated. The initial design is based on a concept from K Sciences, a project subcontractor, that monitors wear progression directly as different optical fibers erode together with the wearing surface. Several problems were encountered with this concept, so Siemens developed an alternative sensor concept. The new concept uses an optical displacement sensor working with an optically transparent spacer that erodes with the wearing surface. In the alternative design, the optical fibers are separated and protected from the harsh wearing environment. Both optical wear sensor designs successfully passed the initial proof-of-concept test requirements. Subsequent prototype testing of the baseline sensor in a more realistic wearing environment did not, however, provide the required measurement accuracy and robustness. The decision was made, therefore, to shift the development focus to the alternate sensor design. This alternative optical wear sensor design provided better measurement accuracy and showed significant promise in solving most of the technical issues inherent to the baseline design.

In the following sections, the baseline wear sensor concept developed by $\mathrm{K}$ Sciences is described, and then the alternative optical wear sensor is described. The sensor designs and laboratory proof-of concept tests are presented.

\subsection{Baseline Fiber Optic Wear Sensor}

\subsubsection{Sensing Mechanism}

The wear sensor that was initially selected for this program is based on K Sciences fiber optic Regression, Erosion, Ablation Sensor Technology (REAST). REAST was developed to monitor the burning rate of solid fuel rocket motors. The technology was demonstrated by $\mathrm{K}$ Sciences in varied critical environments with different wear conditions, including metal cutting milling operation, solid rocket fuel burning, abrasive erosion (rubber and composite braking) and high-temperature melting. The technology monitors wear and wear progression by determining the sensor element length as the sensor tip erodes together with a wearing layer. The working principle of the REAST sensor is illustrated in Figure 13. 


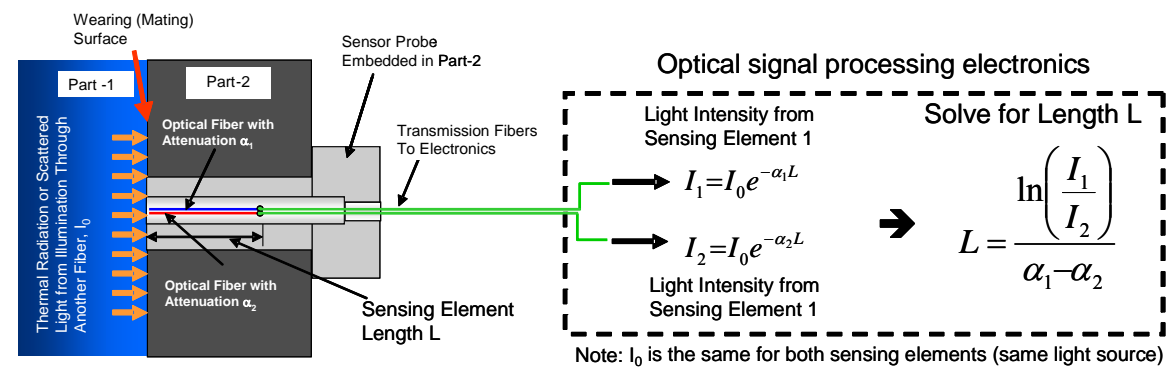

Figure 13: Baseline Fiber Optic Wear Sensor System Schematic

The sensing method is based on Beer's law that states that the optical absorbance varies linearly with the length of an optical medium. The sensor uses two optical fibers of the same length but with different absorption coefficients that erode together with the wearing layer. Assuming the absorption coefficients and other losses of the fibers are known, one can calculate the length of these fibers simply from the ratio of the two transmitted intensities.

The fibers can collect thermal radiation from the hot wearing surface or optical emission from an external light source introduced through a co-located fiber. The selection of the input light source depends on the temperature condition of the wearing part. At low temperature, an external light source is needed

\subsubsection{Laboratory Proof of Concept Tests}

\section{Fiber Length Measurement}

Preliminary testing used a single high-attenuated fiber to evaluate the relationship of detector output to changes in fiber length. To simulate the change in fiber length from wear, a small portion of fiber end was cut after each test run and the fiber end was smoothed using an 800 grit optical file. The fiber was positioned at the same location relative to the incandescent light source during each test run. The experimental setup and the results are shown on Figure 14. The signal changes with fiber length as expected for this fiber with a stated loss of $0.5 \mathrm{~dB} / \mathrm{cm}$.
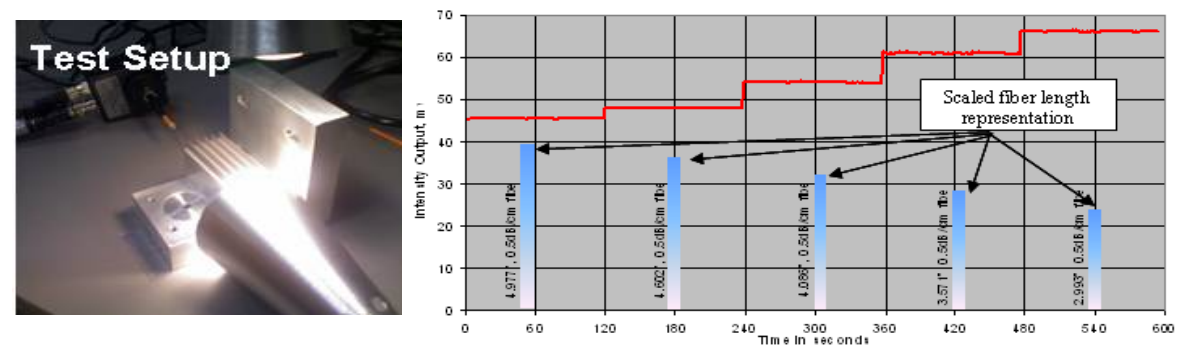

Figure 14: Fiber Transmission as a Function of Length 


\section{High Temperature Tests}

Various tests were conducted to verify the sensing element's functionality at high operating temperatures. These tests included placing the fibers in a blackbody calibration oven and directly heating of the fibers using a torch flame with temperature exceeding $1000^{\circ} \mathrm{C}$. The blackbody calibration test was conducted at varying temperatures ranging from $100^{\circ} \mathrm{C}$ to $910^{\circ} \mathrm{C}$. Aggressive wear simulation tests were also completed with very high temperatures at the localized sparks from the wearing material. In all the tests, the sensing fiber elements provided stable and repeatable signals. The experimental setup as well as an example the optical signals measured during these tests are illustrated in Figure 15.
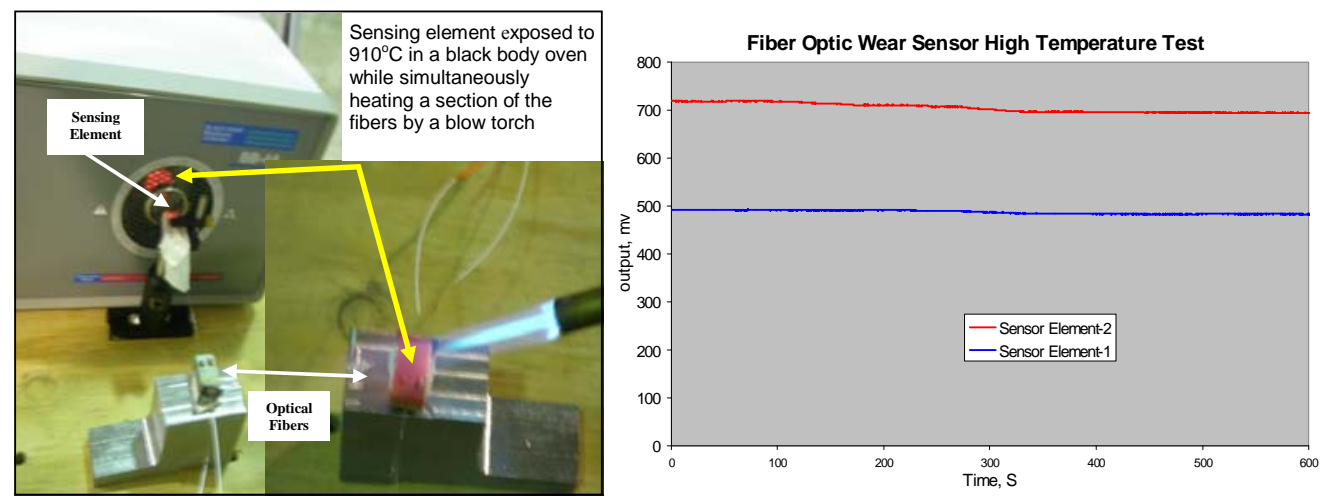

Figure 15: Stable Optical Signal in High Temperature Tests

\section{Wear Simulation Tests}

The fiber optic sensor monitors wear progression by determining the sensing element length as it erodes together with a wearing parts. A series of test runs were conducted to determine wear compatibility of the sensor with metallic parts. We fabricated a probe from stainless steel housing and subjected it to wear by rubbing it against abrasive surfaces and metallic parts. The sensor head construction is shown in Figure 16.

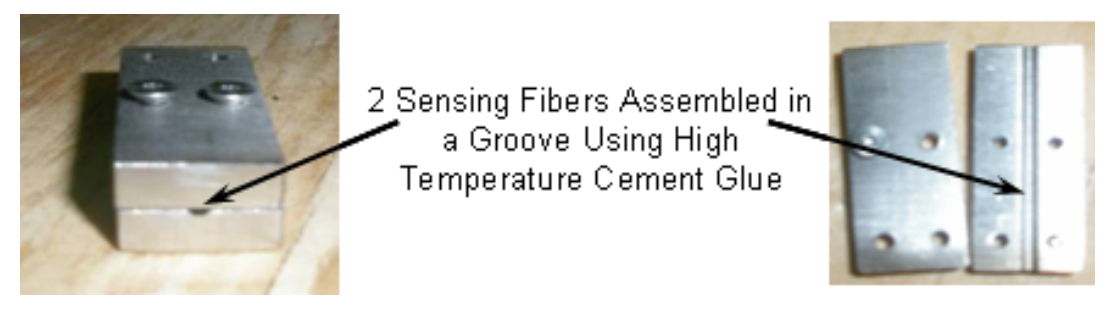

Figure 16: Fiber Sensor Assembly in Simulated Wear Tests 
We observed that the optical fibers become brittle after exposure to high temperature and exhibit very little shear force resistance in a wearing environment. The fibers were, therefore, assembled in a fiber groove and embedded in high temperature cement. Care was taken to eliminate any voids in the cement glue. In this case, only the tip of the fiber erodes together with the wearing surfaces.

We conducted a series of tests to determine the sensor performance in a simulated high speed dynamic wear environment. This was accomplished by wearing the probe on an abrasive wheel of a grinding machine and rubbing it against a spinning metallic part mounted on a lathe machine. In other tests we pressed the probe against a rotating metallic surface mounted on a lathe. These experiments are illustrated in Figure 17.
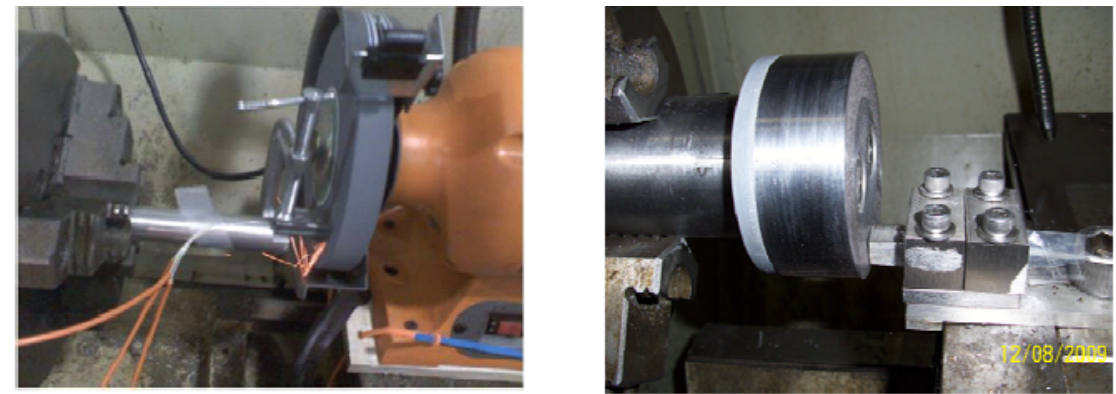

Figure 17: Simulated Wear Experiments Using a Lathe and a Grinder

A linear stage feed mechanism was used to firmly hold the probe and feed to probe tip in order to wear at a controlled rate.

In all the tests, the sensor was able to distinguish the optical input signals from the heat generated at the wearing surfaces. Vibration, mechanical chatter, and particle sparks, however, made it difficult to get reliable and useful data. Most importantly, any variation in the fiber end finish resulting from wear lead to large changes in the optical intensity picked up by each sensing element. Typical results are shown in Figure 18.

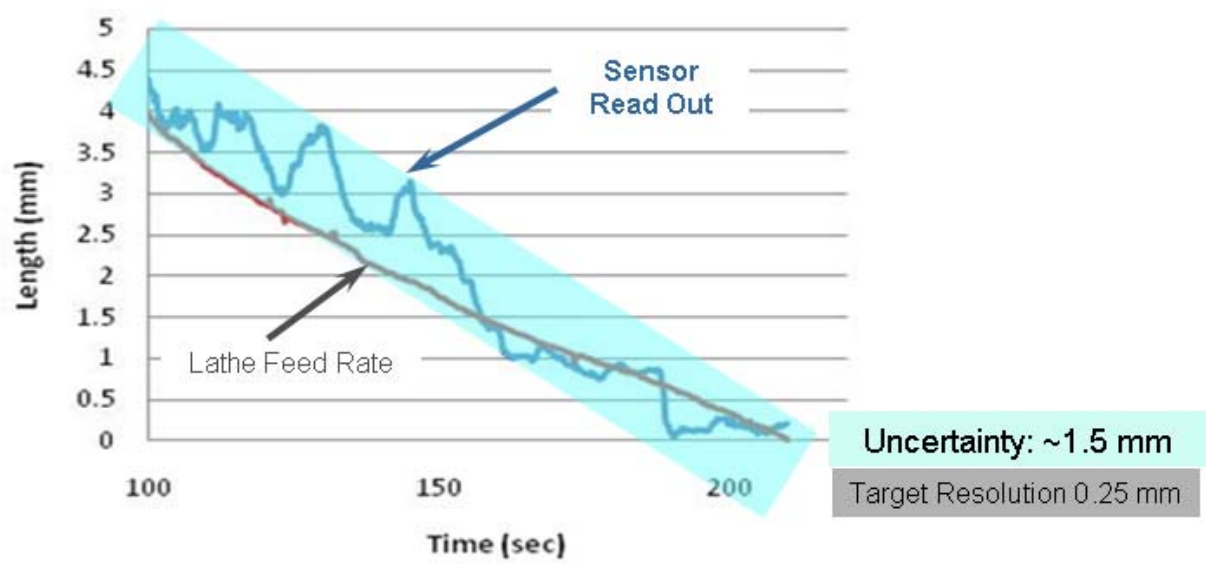

Figure 18: Fiber Sensor Length as a Function of Wear Rate. 
The feed rate of the lathe and the signal from the optical wear sensor are highly correlated. The sensor signal, however, shows considerable noise and fluctuations over time. Converted to fiber length, the measurement uncertainty was larger than $1.5 \mathrm{~mm}$, much higher than the target resolution of $0.25 \mathrm{~mm}$. This uncertainty could not reduced by time averaging.

The wear simulation tests revealed several technical issues and operating capability limitations. The presence of random fractures of the fiber's end finish from the wearing process, vibration, mechanical chatter, and various optical noises made it difficult to get reliable data. Random variations in the sensing element's fiber end finish and end fractures varied the amount of light picked up by each of the sensing elements. The results could be improved when multiple fibers were used in a fiber bundle configuration but not to the point where the sensor accuracy would come close to the required value.

\subsubsection{Limiting Factors in Baseline Wear Sensor}

Design improvements were made to the baseline design to improve sensor performance and measurement accuracy. Some of the technical issues, however, were still not fully resolved to get the required measurement accuracy and wear monitoring capability outlined in the wear development specification. These technical issues are inherent to fiber optic materials, and they may not be easily resolved. Outstanding technical issues that still need to be resolved include:

- The part wearing processes in the combustion section are not expected to produce consistent fiber end finish for the two groups of sensing elements in the probe. This would impact the sensor's measurement.

- Wear sensor performance is sensitive to the sensing element fiber orientation receiving optical signals from the wearing layer. If the fiber end orientation does not stay consistent through out the wearing process, it will impact measurement accuracy.

- The presence of various optical noises in a dynamic wear environment requires advanced optical noise filtering methods.

- The effect of long duration exposure to high temperatures on fused silica fibers is not fully understood. Doping material of the high-attenuated fiber is known to be affected at temperatures above $1000^{\circ} \mathrm{C}$. Preliminary blackbody oven laboratory testing of the fibers at more than $900^{\circ} \mathrm{C}$ for four hours showed the measured output drifted with time. Further study is required to understand the extent of drift and develop any needed heat treatment processes for the sensing fibers

- Sensors are sensitive to the quality of fiber splice and connector joint assembly, and, therefore, a robust and reliable probe fabrication process is required

We decided it was unlikely that we would find solutions to all of the above technical issues within the remaining budget and development schedule. As risk mitigation, an 
alternate optical wear sensor was developed in parallel that showed promising results in resolving most of the issues inherent in the baseline design. The alternate wear sensor design was, therefore, given priority for development. A description of the alternative concept and its test results are presented in the next section.

\subsection{Alternative Fiber Optic Wear Sensor}

The alternative optical wear sensor was developed as risk mitigation for the first design. The sensor is also based on fiber optic technology but overcomes most of the limitations that were identified in the original K Sciences sensor design.

\subsubsection{Sensing Mechanism}

Figure 19 illustrates how an optically transparent wear guide that erodes together with the wearing part can protect the fiber end facets so that fiber breakage and uncontrolled fiber finishes are avoided.
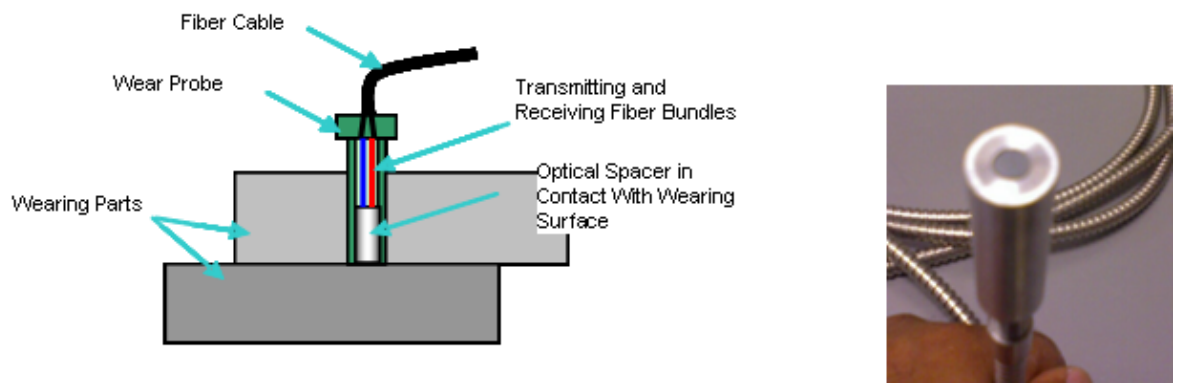

Figure 19: Alternative Wear Sensor: Implementation of an Optical Wear Guide

Other drawbacks of the original design result from its sensitivity to the launch conditions of the light and problems to consistently and reliably splice fibers with very different loss coefficients. To alleviate these problems, the new sensor design also entails changes to the fiber optic sensing mechanism. The alternate optical wear sensor design uses an optical distance sensor offered commercially by PHILTEC, Inc. This type of sensor was used by Siemens for gap measurements in gas turbines. The basic measurement principle is illustrated in Figure 20.

Light from a transmitting fiber bundle diverges, and it is partially reflected, under an angle from the target surface. The amount of light that is then collected by a neighboring receiving fiber bundle is a function of the distance of the fiber bundles from this target. As the sensor is moved away from the target, the amount of light collected by the receiving fiber bundle goes through a maximum as illustrated on the right side of 

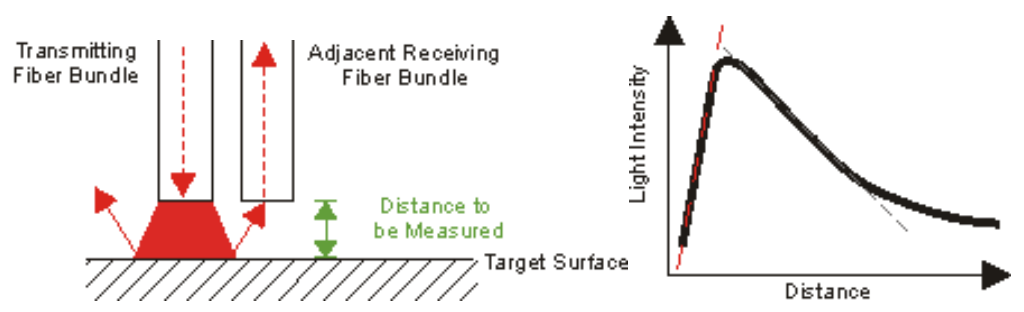

Figure 20: Measurement Principle of the Fiber Optic Gap Sensor

Figure 20. The sensor is typically operated on the far side falling slope where the signal is approximately linear to the size of the gap between the sensor and the target.

Changes in the reflectance of the target can be compensated by reference receiving fibers that are intermixed with the transmitting fibers. Figure 21 shows the packaged fiber tip of a PHILTEC gap sensor that contains three fiber bundles. Transmitting fibers send light from a light source to the target. Reflected light is collected by a neighboring receiving fiber bundle connected to a photo detector. Reference receiving fibers are intermixed with the transmitting fibers and connected to a second photo detector. For clarity, the sensor was illuminated and transmitting fibers appear bright in the photograph taken with an IR sensitive camera.

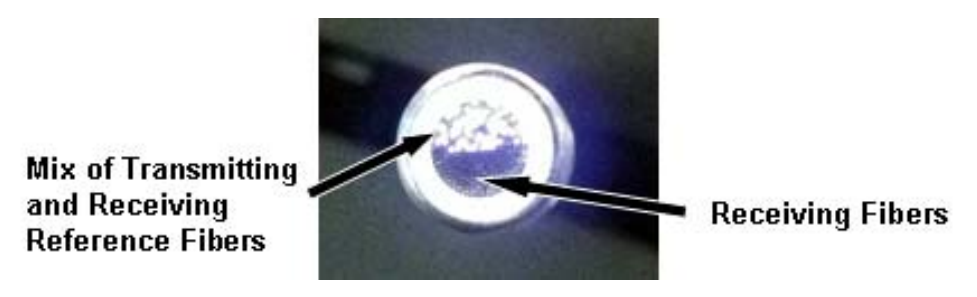

Figure 21: Fiber Tip of a Reflectance Compensated PHILTEC Gap Sensor

The sensor tip that transmits and receives the optical signals is separated from the wearing surface by an optical media made of high temperature fused silica. This optical spacer prevents damage of the sensor fiber end polish from rubbing against the wearing surface. The outside of the wear probe housing can be configured into different shapes to satisfy any specific application requirements. 


\subsubsection{Alternative Wear Sensor System Design}

The basic elements of the alternative optical wear sensor system are shown in Figure 22:

1. The optical wear spacer is mounted inside the sensor housing, and it wears together with the wearing part.

2. The fiber optic probe tip is where all fibers are mounted flush with the wear spacer.

3. A high temperature fiber optic cable transmits light. It needs to withstand temperatures and conditions inside the turbine casing.

4. A fiber optic connector that connects to a second fiber optic cable.

5. A low temperature fiber optic cable is used to connect the sensor to the electro optic components outside of the engine.

6. An electro-optics enclosure contains 1) an $800 \mathrm{~nm}$ light source connected to the transmitting fiber bundle, 2) optical detectors connected to the receiving and the referencing fiber bundles, 3) drive electronics for the light emitting diode (LED), 4) circuitry for the photo detectors, and 5) digitizing and signal conditioning electronics.

7. A computer connected to the electro-optics box with processing software and a graphical user interface.

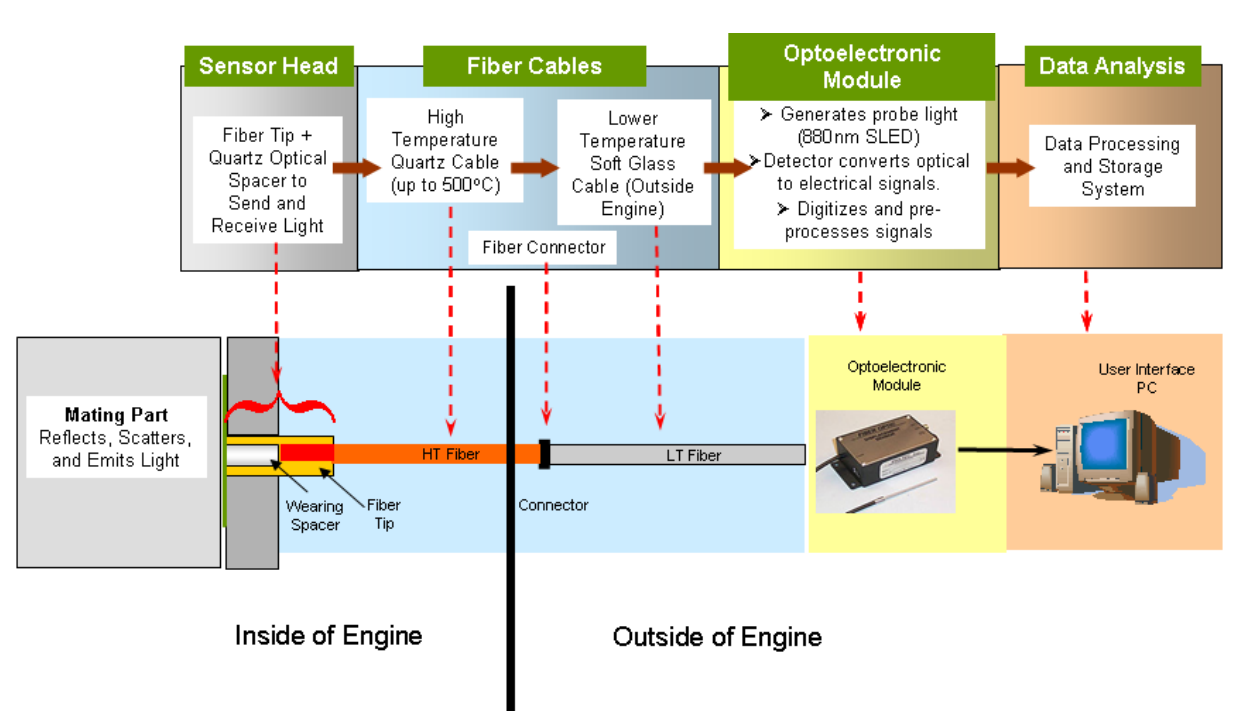

Figure 22: Components of the Alternative Wear Sensor System 


\subsubsection{Wear Simulation Tests}

Experiments were conducted in the lab to evaluate the new sensor design performance and measurement accuracy in a dynamic wear environment. Testing was similar to the | simulated wear tests performed with the original wear sensor. Figure 23, illustrates experiments using the high-speed abrasive wheel of a bench grinder. The setup is shown, along with a photograph of the preliminary prototype sensor used in these experiments. The sensor was mounted on a computer controlled translation stage and the spatial resolution of this setup was $0.025 \mathrm{~mm} / \mathrm{rev}(0.0001 \mathrm{inch} / \mathrm{rev})$. A dedicated LabView program was developed to analyze the wear information.
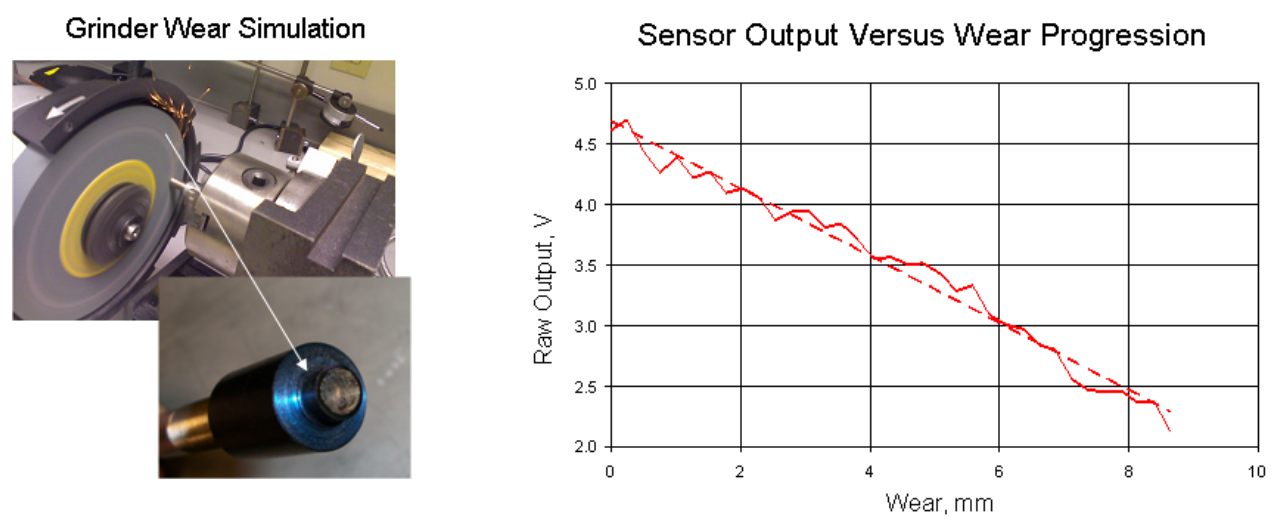

Figure 23: Wear Simulation from Grinder Experiments

The sensor output varied linearly with the linear feed and wear progression and the measurement uncertainty and accuracy of this new sensor design was $\pm 300 \mathrm{um}$, less than half of the uncertainty we could reach with the original sensor design. The alternative wear sensor showed much better stability, accuracy, and repeatability in this simulated wear environment.

\subsubsection{High Temperature Tests}

Due to the choice of materials the alternative prototype sensor used in the above dynamic wear experiments cannot be used at operating temperatures above $500^{\circ} \mathrm{C}$. For higher temperature operation, the optical fiber assembly had to be changed. A new prototype was fabricated with fused silica fiber and used in all high temperature tests. 


\section{Experimental Setup}

High temperature testing was conducted by heating the sensor and assessing the effect of temperature on the response and integrity of the sensor. To reach temperatures of up to $1000^{\circ} \mathrm{C}$, the experimental setup shown in Figure 24 was developed.

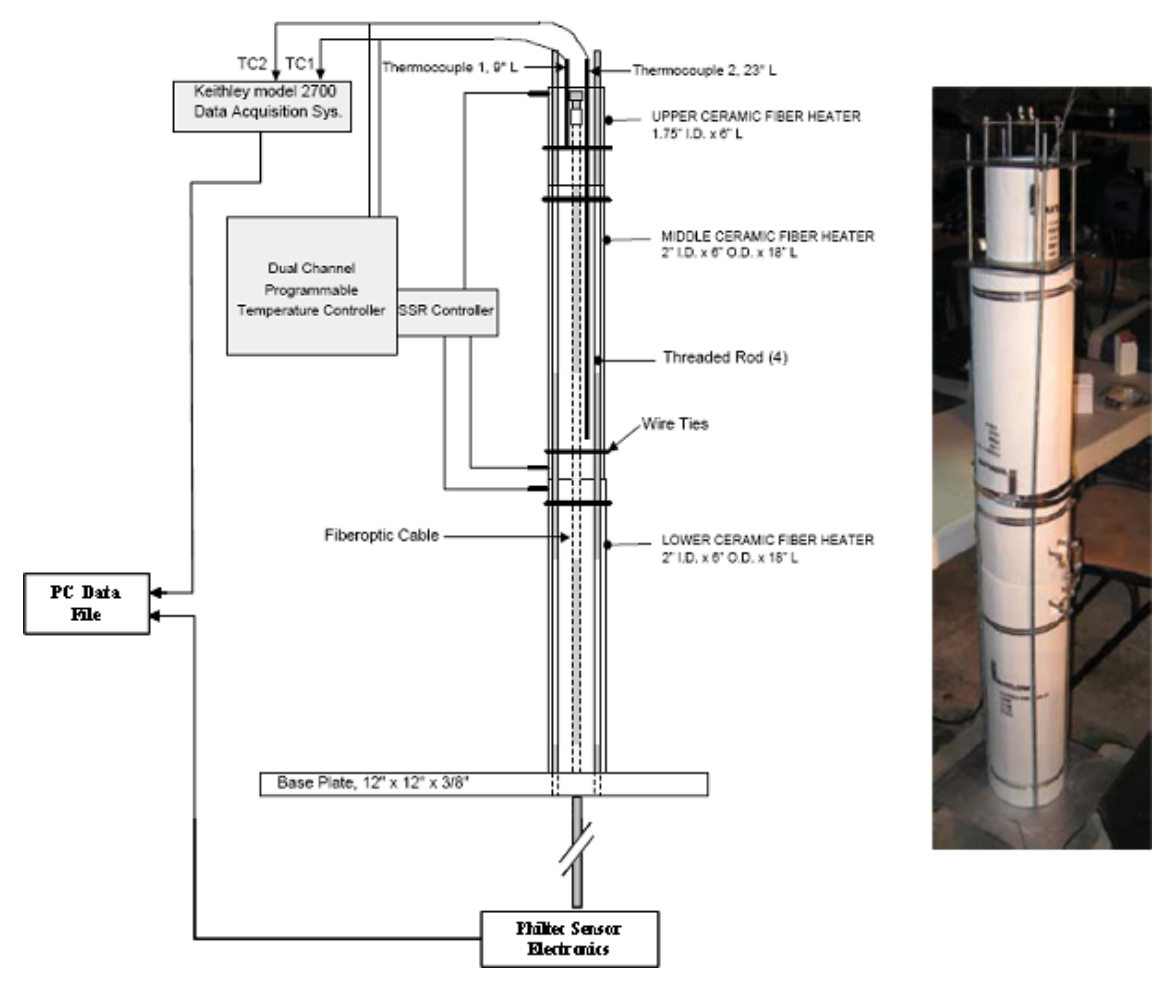

Figure 24: High Temperature Test Setup

A vertical stack of ceramic heaters was used to heat the sensor tip plus one meter of cable length. The stack was comprised of two $50 \mathrm{~cm}$ (20 inch) long, $1500 \mathrm{~W}$ heaters with a $15 \mathrm{~cm}$ (6inch), $350 \mathrm{~W}$ unit on top, providing a total heated length of $120 \mathrm{~cm}$. Two steel top plates were machined to secure the top heater and provide support for the mounting bracket and thermocouple mounts. Two K-type thermocouples and a Watlow dual channel temperature controller were used to control the heating and cooling of the fiber optic sensor tip and cable. A glass target was cemented to a Hastelloy metal bolt to provide a constant gap during the heat profile testing.

Although the heater was rated for $1000^{\circ} \mathrm{C}$, the first heat run data showed the heater could not elevate the temperature beyond $600^{\circ} \mathrm{C}$ when the controller was programmed to $1000^{\circ} \mathrm{C}$. After the heater was wrapped with fiberglass insulation, the temperatures peaked out at $780^{\circ} \mathrm{C}$. To obtain temperatures of up to $1000^{\circ} \mathrm{C}$, the $350 \mathrm{~W}$ heater was 
replaced with a $50 \mathrm{~cm}$ long $1500 \mathrm{~W}$ heater. The temperature distribution inside the oven had a relatively large gradient; the temperature difference between the center of the oven and the sidewalls was as much as $200^{\circ} \mathrm{C}$. Care was taken to place thermocouples as close as possible to the probe location to assure representative temperature measurements.

\section{High Temperature Prototype}

For operation at temperatures up to $1000^{\circ} \mathrm{C}$, we modified the sensor tip and fiber cable. Standard borosilicate glass, typically used for fiber bundles, has a melting point around $820^{\circ} \mathrm{C}$, and is annealed around $550^{\circ} \mathrm{C}$. Quartz glass melts at much higher temperatures around $1665^{\circ} \mathrm{C}$, and is usually annealed at $1140^{\circ} \mathrm{C}$. We, therefore, used fused silica fibers with a pure silica core and fluorinated cladding for the high temperature fiber optic cable.
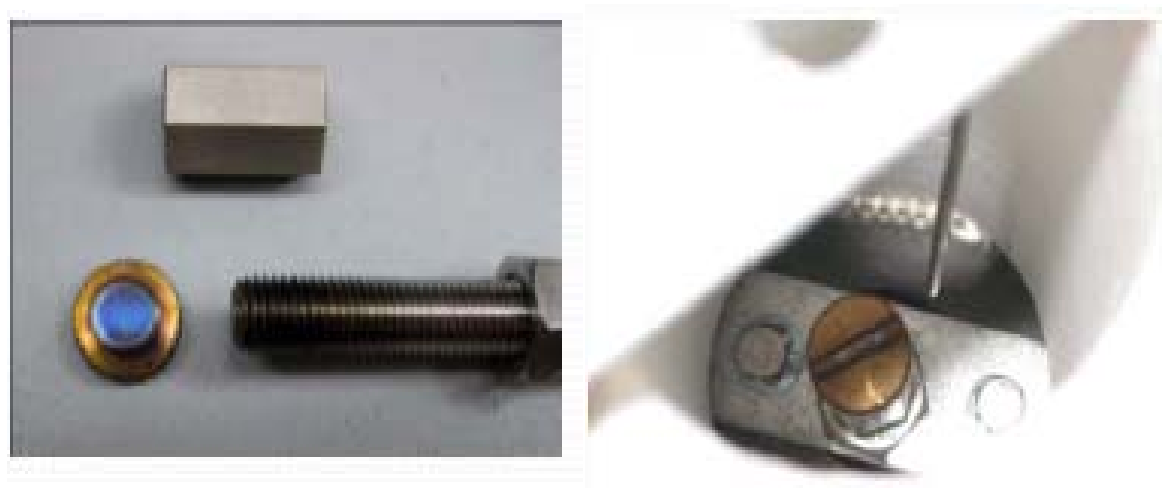

Figure 25: High Temperature Prototype

The diameter of these fibers is about $\sim 150 \mu \mathrm{m}$, several times larger than fibers made from soft borosilicate glass. For mechanical protection, the fibers are coated with clear high temperature polyimide coating. The polyimide material has no melting point, but a glass transition temperature of $300-350^{\circ} \mathrm{C}$. At temperatures higher than $600^{\circ} \mathrm{C}$, the polyimide is expected to carbonize and flake off. To study the effect of the coating on the sensor performance at high temperatures, we also fabricated short $(2.54 \mathrm{~cm})$ probe tips with and without coating and exposed them to high temperatures. Chemical etching was used to remove the fiber coating at the fiber tips before assembly. The housing for the fiber tip and the spacer were machined from the high temperature alloy Hastelloy with oxidation resistance of $1900^{\circ} \mathrm{F}$ and strength up to $1800^{\circ} \mathrm{F}$.

To allow calibration of the sensor at high temperatures, we developed a special fixture that incorporates a Hastelloy nut that holds a glass target and can be screwed onto the fiber tip (Figure 25). The glass target was cut and ground from flat automotive window float glass with black enamel paint coating on the backside. Using a screwdriver, we were able to change the distance between the fiber tip and the target. 


\section{Testing Sensor to $450^{\circ} \mathrm{C}$}

In the first phase of high temperature testing, the probe tip was heated to $450^{\circ} \mathrm{C}$ while the transmission cable remained at room temperature. The sensor was brought up to full temperature in $50^{\circ} \mathrm{C}$ steps of 10 minutes each, and then soaked at maximum temperature for four hours. The sensor response was monitored during, before, and after the heating cycles and did not change during or after the sensor was heated to $450^{\circ} \mathrm{C}$ for more than 12 hours. A second test involved manual calibration of the probe at $400^{\circ} \mathrm{C}$. In this test, a long screwdriver was used to rotate the hex nut-target assembly target opening the gap in steps of 1/6 turn (6.9 mils). The results are shown in Figure 26 below and are charted along with two room calibrations performed before and after the heating. The result showed no significant difference among these three calibrations; two at room temperature and one at $400^{\circ} \mathrm{C}$.

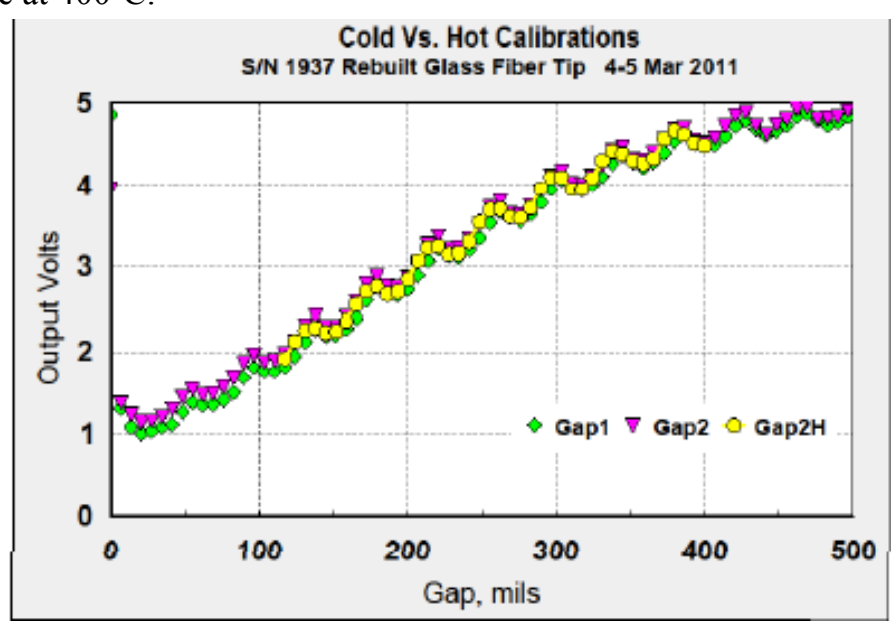

Figure 26: Room Temperature and $450^{\circ} \mathrm{C}$ Calibrations

\section{Testing Sensor to ${ }^{1000}{ }^{\circ} \mathrm{C}$}

During the first high temperature tests when the temperature was gradually increased to $1000^{\circ} \mathrm{C}$, we observed erroneous sensor readings. A visual inspection of the probe indicated that fouling was from the degradation of ceramic glue used to bond the fiber bundle. For subsequent tests, PHILTEC repackaged the probe tip using a better ceramic adhesive. At the end of the heating tests, however, the rebuilt probe tip was still contaminated with burned material, indicating the source of the fouling could be from the polyimide buffer coating of the fibers. Figure 27 shows the fiber tip and hex nut after two heating runs. During the subsequent tests, PHILTEC improved the test setup and limited the heating to $800^{\circ} \mathrm{C}$. These changes improved the test conditions and reduced the fouling issues. 

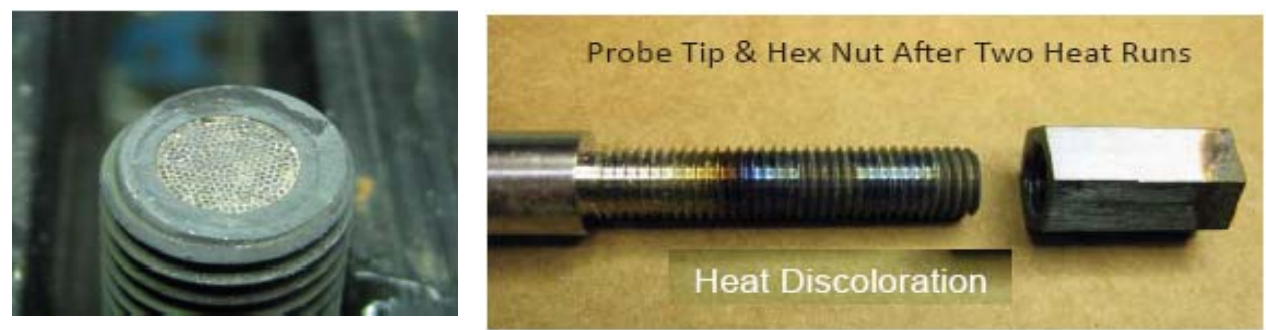

Figure 27: Fiber Tip after Heating to $780^{\circ} \mathrm{C}$

Figure 28 shows the results of a 16-hour high temperature test. A ceramic rod was selected as target and bonded to the hex nut with ceramic adhesive. The heater was ramped up to $600^{\circ} \mathrm{C}$, held that temperature for 1 hour then turned off before a second heat ramp up to $780^{\circ} \mathrm{C}$ where the sample was held for 4 hours. During the test, we noted that the sensor performed normally up to $600^{\circ} \mathrm{C}$. Above that temperature, the sensor signal increased far above its set point, and then instantly dropped when the heater was shut off. During these periods, the calculated gap was considerably larger than realistically possible. This signal increase is most likely due to thermal radiation either from the ceramic rod that may be aglow or from the oven itself. The signal dropped instantly

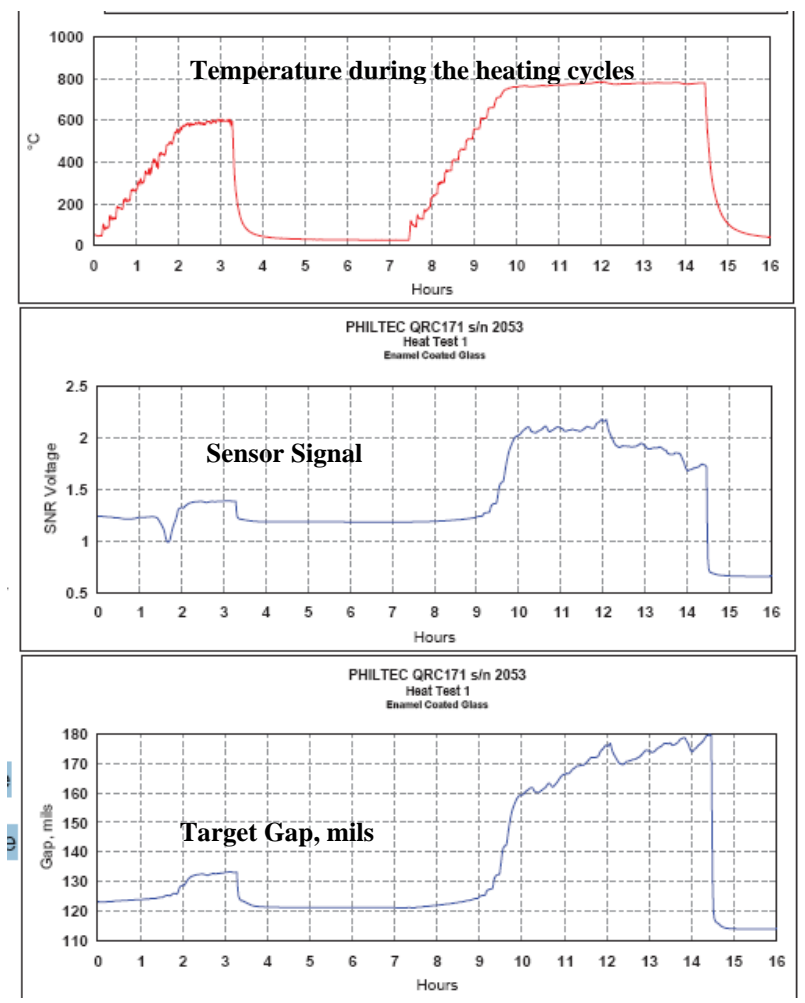

Figure 28: High Temperature Tests of the Probe Tip 
when the heater was turned off confirming this assumption. The heater was removed and the parts inspected. The ceramic target was in perfect condition but the probe tip, fibers and hex nut showed heat discoloration.

\section{Fiber Tip Contamination}

The effect of the polyimide buffer coating of the fibers on the probe performance was evaluated by comparing two $2.54 \mathrm{~cm}$ short silica fiber bundles. The samples were bonded into solid $53 \mathrm{~mm}(1 / 4 \mathrm{inch})$ diameter by $15 \mathrm{~cm}$ (6 inch) long stain steel SS309 rods. Sample 1 included polyimide buffer coating and Sample2 fibers had the buffer coating chemically removed before assembly. The samples were mounted on a base plate using a compression fitting with the face of the fiber optics $6.3 \mathrm{~cm}$ above the base plate, thereby exposing $3.8 \mathrm{~cm}$ of the rod to the heat zone. Three runs were made for each sample with a 4 hours heat soak at $800^{\circ} \mathrm{C}$ followed by shutdown. The result showed limited fouling as a result of the burned polyimide coating. The silica fibers and ceramic adhesive were in good condition after 12 hours exposure to $800^{\circ} \mathrm{C}$. The fiber buffer coating removed sample (Sample 2) appears to be a cleaner fiber bundle after an exposure to $800^{\circ} \mathrm{C}$.
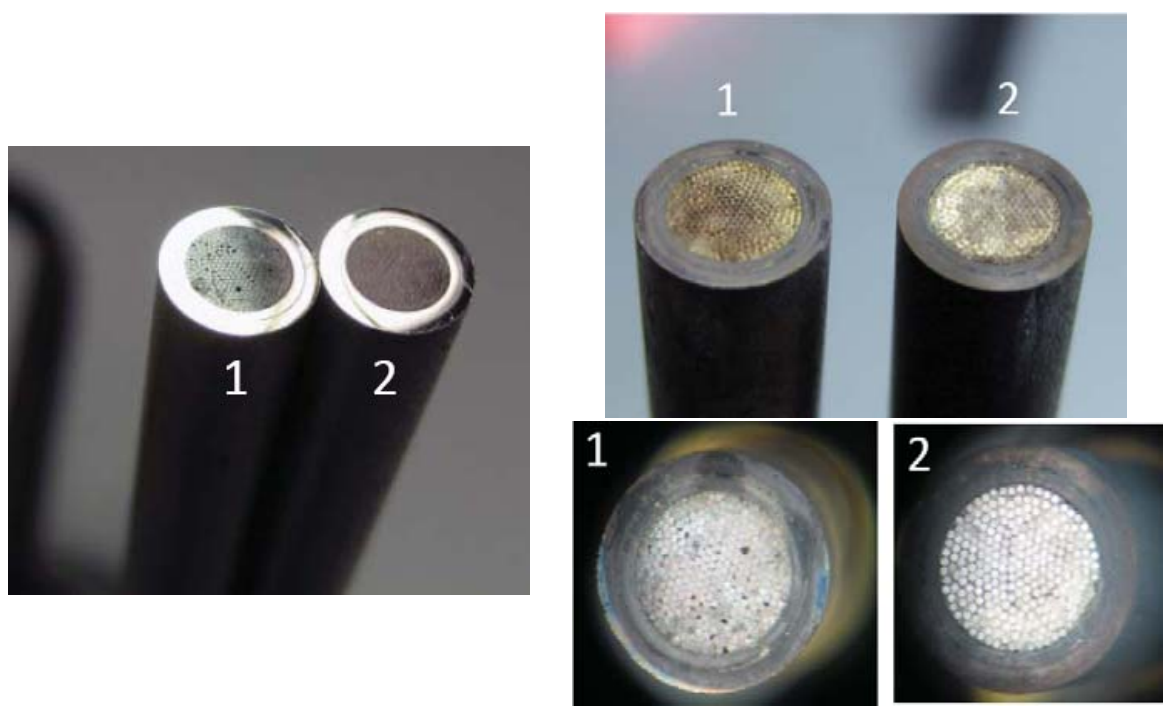

A) Samples before heating

B) Samples after heated to $800^{\circ} \mathrm{C}$

Figure 29: Coated and Uncoated Fiber Bundle Heating Test 


\section{Thermal Radiation Compensation}

To eliminate the effect of thermal radiation on the sensor performance, design changes were implemented on the LED light control and signal processing of the sensor system. New system capability was added to measure the background noise level by turning on and off the LED light at regular intervals and continuously processing the detector outputs. The detector output when the LED is off comes from the background optical noise, and that is subtracted from the detector output when the LED is on. This new capability will allow isolation of all background noise and surface effects during the measurement.

\subsection{Wear Sensor Evaluation}

Laboratory tests proved that the alternate sensor design is a promising approach. Table 3 summarizes the performance of both wear sensors, comparing them to the requirements established for the wear sensor application in the combustion zone of a gas turbine.

Table 3: Comparison of Wear Sensor Performance

\begin{tabular}{|c|c|c|c|}
\hline Criteria & Specifictions & $\begin{array}{c}\text { Baseline/ } \\
\text { K Science }\end{array}$ & $\begin{array}{c}\text { Alternative/ } \\
\text { Philtec }\end{array}$ \\
\hline Distance operating range, $\mathrm{mm}$ & $0-10$ & $0-10$ & $0.2-12.7$ \\
\hline Maximum operating temperature, C & 1000 & 1000 & 800 \\
\hline Instability, room temperature, um & $25-250$ & 740 & 2 \\
\hline Instability, operating temperature, um & $25-250$ & $\mathrm{NA}$ & 30 \\
\hline Uncertainty during wear, um & $25-250$ & 1500 & 300 \\
\hline
\end{tabular}

The alternative wear sensor seem to be appropriate for operating temperatures of up to $800^{\circ} \mathrm{C}$, and wear measurement uncertainties of less than $0.3 \mathrm{~mm}$ were obtained with the revised design. Based on this sensor performance evaluation, we preceded to design and prototype a sensor system in a gas turbine. 


\section{Engine Demonstration}

.A design review package was completed and Siemens identified an engine for the prototype system demonstration test. Engine demonstration of the wear sensor system occurred with an installation in March 2012 on an F-Class engine located in Florida

The floating transition seal was selected for the sensing technology validation. Two sensors were installed on the same combustion basket of the engine, monitoring the thickness of the outer transition seal.

\subsection{Installation Design}

Two sensors were installed at the transition seal of an F-Class gas turbine. The combustion system in this engine class consists of 16 can-annular combustors. Each combustor has an air-cooled transition piece that directs the combustion gases to the $\mid$ turbine blades. As indicated in Figure 30 the sensor will be installed at the transition seal of combustor Basket 2 at the outer diameter (OD) floating seal.

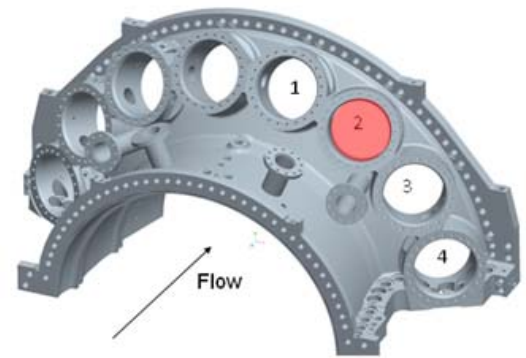

Figure 30: Location of Basket 2 in Combustor Casing

Figure 31 shows the target position for the installation of two wear sensors at the OD floating seal. The left side displays an external view of the engine with part of the vane
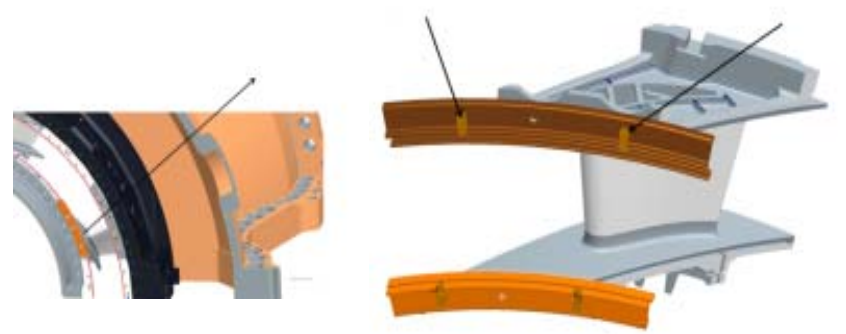

Figure 31: Views of Vane Carrier and Installation Location of Wear Sensors.
Formatted: Font: Times New Roman, 12 pt

Formatted: Font: Times New Roman, 12 pt, Check spelling and

Deleted: Figure 30
Formatted: Font: Times New Roman, $12 \mathrm{pt}$

Deleted: Figure 31 
carrier displayed. The right side shows the floating seal and sensor location with respect to the first row turbine blade. Figure 32 shows a detailed view and schematic of the sensor assembly and plug location within the 2-part floating seal. The right hand side of | Figure 32, shows the optical plug (yellow) assembled onto the seal (gray). It is threaded to accommodate the fiber optic cable (green). The fiber optical cable will be attached to the optical plug and routed out through the blade ring to an egress point located on the combustion casing near man way cover.

The instrumentation will consist of an optical plug welded to the floating seal, a fiber optic cable and a sensor unit. If the floating seal experiences wear, the optical plug will erode. The fiber optic cable will be routed through the modified vane carrier to an egress $\mid$ hole in the casing. Figure 33 illustrates the routing path for the fiber optic cable from the transition seal along the inner wall of the engine casing and out through the casing.

The fiber optic cable will be secured to the vane carrier by Ni-Chrome tack strap. Once the fiber optic cable exits the vane carrier, it will be bundled with the adjacent OD fiber optic cable into a flex tube. The fiber optic cable will exit the casing via a pre-machined hole.

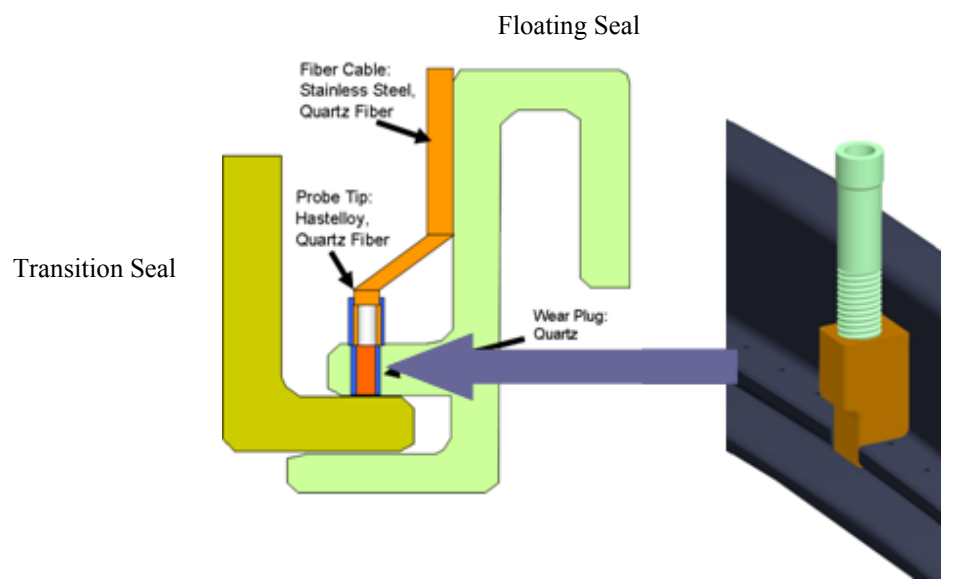

Figure 32: Schematic of Wear Sensor Installation.

Routing and exit potting through casing will be performed per the standard operating processes. The photograph shows an example of the flex tube routing from a previous sensor installation.
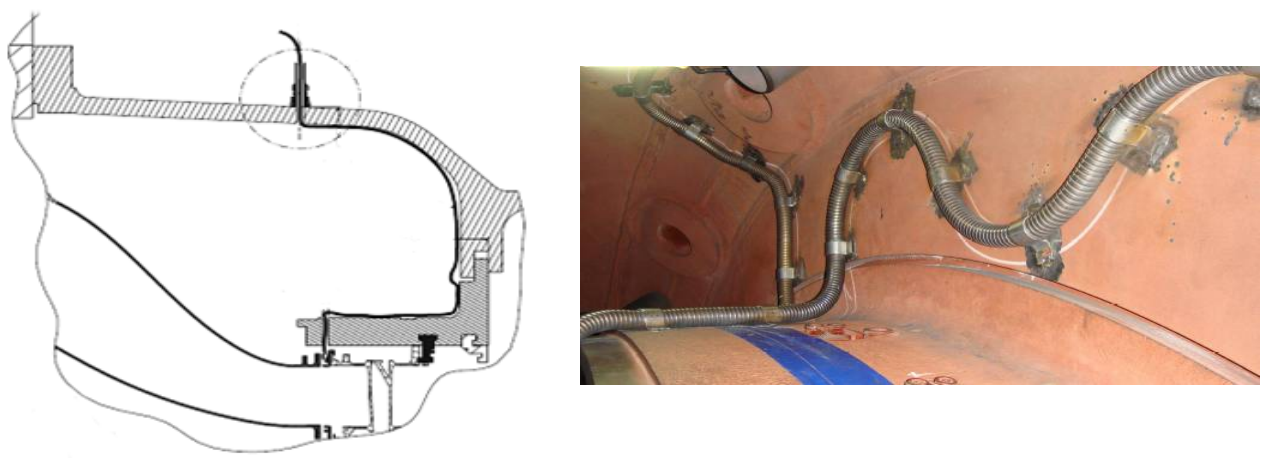

Deleted: Figure 32

Formatted: Font: Times New Roman, 12 pt

Deleted: Figure 32

Formatted: Font: Times New Roman, 12 pt

Formatted: Font: Times New Roman, 12 pt

Deleted: Figure 33 


\subsubsection{Wear Sensor System}

An integrated sensor and wear plug system was built and tested at both Siemens and PHILTEC laboratories. The high temperature sensor system comprises an optical quartz plug, a high-temperature quartz fiber cable, a low-temperature glass fiber cable, a PHILTEC digital displacement sensor (muDMS-RC171) as well as a software interface. The sensor system layout and components are shown in Figure 34.

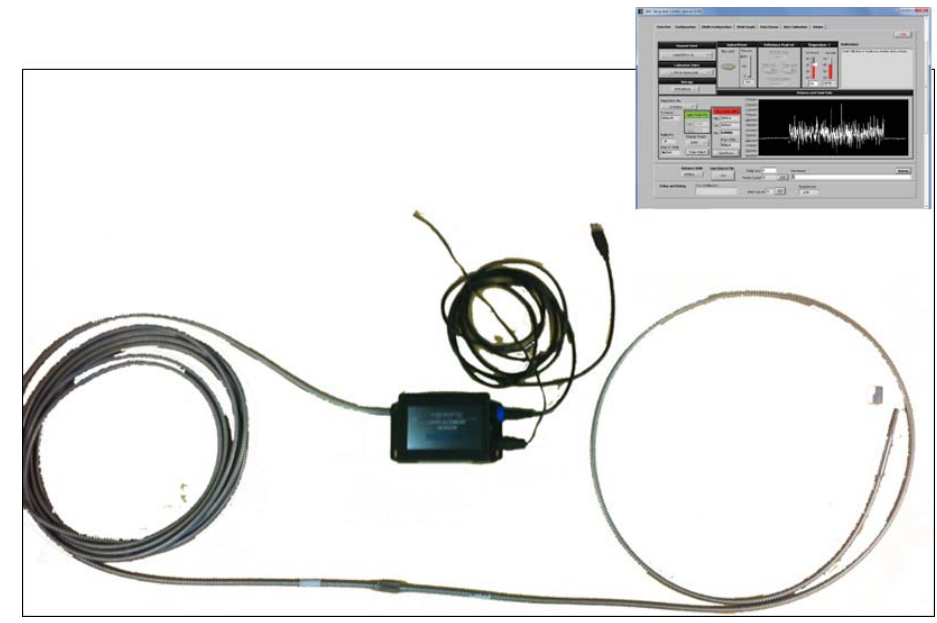

Figure 34: Layout of the Complete Wear Sensor System

It comprises the wear spacer, a solid fiber tip, the high temperature fiber cable, a fiber connector, the low temperature fiber optic cable, the electro-optic interrogation unit, power supplies, a PC, and the custom designed software. The following paragraphs describe the actual materials used in the construction of the system.

\section{Optical Spacer}

The optical wear spacer is the part that is exposed to the highest temperatures, $\sim 800^{\circ} \mathrm{C}$. It is based on a $12 \mathrm{~mm}$ thick transparent quartz window encased in stainless steel Hastelloy housing. The wearing surface of the quartz spacer is machined on a grinder while the opposite side where the fiber tip is located is polished to a good optical quality. Figure 35 shows the structure.

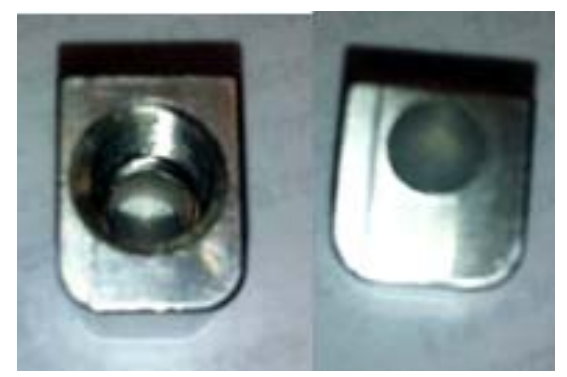

Figure 35: Optical Wear Spacer 


\section{Solid Fiber Tip}

The threaded fiber tip is located at the end of the high temperature cable and screws into the optical wear spacer as shown in Figure 36. Three fiber bundles are rearranged and glued into a solid tip using high temperature ceramic-based epoxy. The right side of Figure 36 shows the detail of the fiber end facet. The photograph was taken with the cables connected to the electro-optic unit with the LED on using a camera that is sensitive to infrared light. It can be seen that the fiber tip is divided into two half-moon shaped areas. The upper area shown in the photograph contains 75 fibers that are sending light at a wavelength of $800 \mathrm{~nm}$ towards the fiber tip. This transmitting bundle is intermixed with 75 receiving fibers that appear dark in the photograph. They receive the reference signal used to correct for changes in the target reflectivity. These fibers are connected to a photodiode. The lower area of the fiber tip contains 150 receiving fibers that are connected to the second photo detector. They are used to measure the distance of the fiber tip from the reflecting surface.

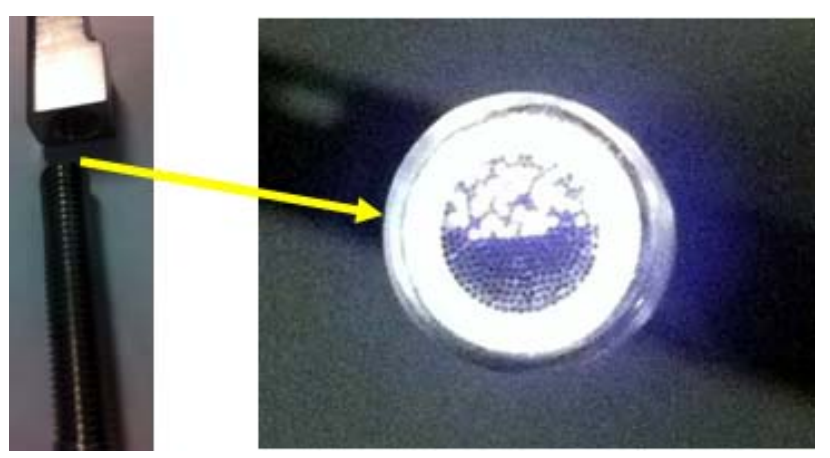

Figure 36: Fiber and Optical Wear Spacer Assembly

The solid tip is about $5 \mathrm{~mm}$ long and the fibers are held in place by an alumina ferrule with an inner diameter of $4 \mathrm{~mm}$. Fibers are glued using high temperature ceramic epoxy. The individual optical fibers are multimode fibers with a core diameter of 150 micrometer. Fiber core and cladding are made of pure fused silica (quartz), and the fiber coating was removed.

\section{High Temperature Fiber Cable}

The high temperature fiber optic cable is approximately $3 \mathrm{~m}$ long and is used to guide the light in and out of the engine casing. Temperatures inside the casing are expected to be on the order of $450^{\circ} \mathrm{C}$. The fibers are constructed of a silica core and a fluorine doped silica cladding and coated with polyimide. Figure 37 shows a photograph of the high temperature fiber as well as the connector facet. The three fiber bundles are protected by stainless steel sheathing and routed to a fiber connector that is located outside of the 
engine and connects the high temperature and low temperature fiber cables. The end face of the connector is shown in the right hand side of Figure 37. The three fiber bundles are clearly visible. They are assembled into and held by stainless steel spring rings with a diameter of the optical apertures of $2 \mathrm{~mm}$ for the transmit and reference fibers and $3 \mathrm{~mm}$ for the adjacent receiving fibers. No epoxy is used in this connector.

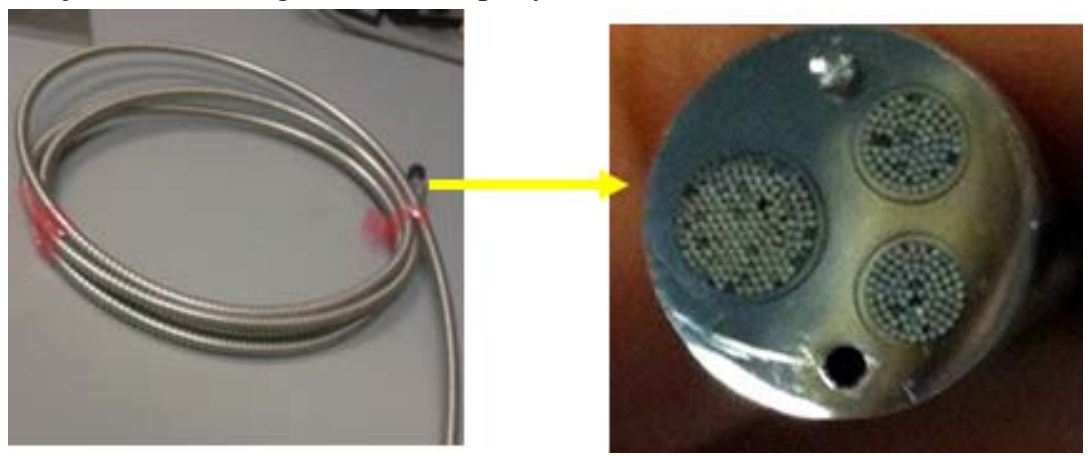

Figure 37: Armored High Temperature Cable and Connector Facet

\section{Low Temperature Fiber Cable}

Whereas the high temperature fiber optic cable contains 300 quartz multimode fibers with a diameter of 150 micrometers, the low temperature fiber optic cable consists of thousands of smaller diameter $(<50 \mu \mathrm{m})$ fibers made of standard borosilicate glass. This fiber has a smaller bend radius and fibers are coated with regular high temperature epoxy.

The end face of the low temperature fiber connector is shown in Figure 38. The photographs were taken with an IR sensitive camera, the transmitting fiber bundle shows up bright in the right hand side of the figure. The fibers are much smaller and fused at the fiber connector. No epoxy is used in the construction of the fiber connectors.

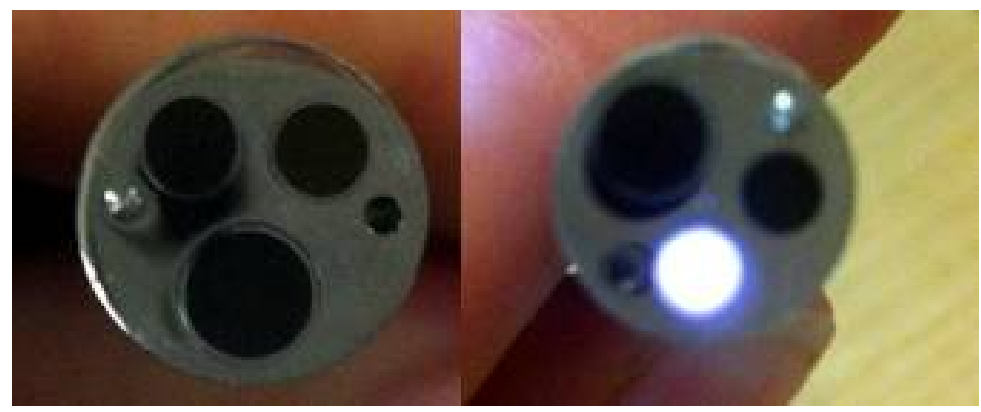

Figure 38: Fiber Connector - Low Temperature Cable 


\section{Interrogator and Electro-Optics Enclosure}

The electro-optic enclosure is designed to be located next to the engine inside the turbine enclosure where temperatures are as high as $\sim 45^{\circ} \mathrm{C}$ during the day. It contains the two PHILTEC interrogator units, all power supplies needed, as well as a USB hub and USBEthernet transceivers. All electronics are rated to withstand temperatures of up to $70^{\circ} \mathrm{C}$. The optical detectors inside the interrogator are temperature stabilized by heaters and the maximum temperature is $50^{\circ} \mathrm{C}$. Provisions have been made, therefore, to cool the enclosure either by fans (as shown in Figure 39: Electro-Optics Enclosure with Cooling Fans) or via a commercial air conditioning unit.
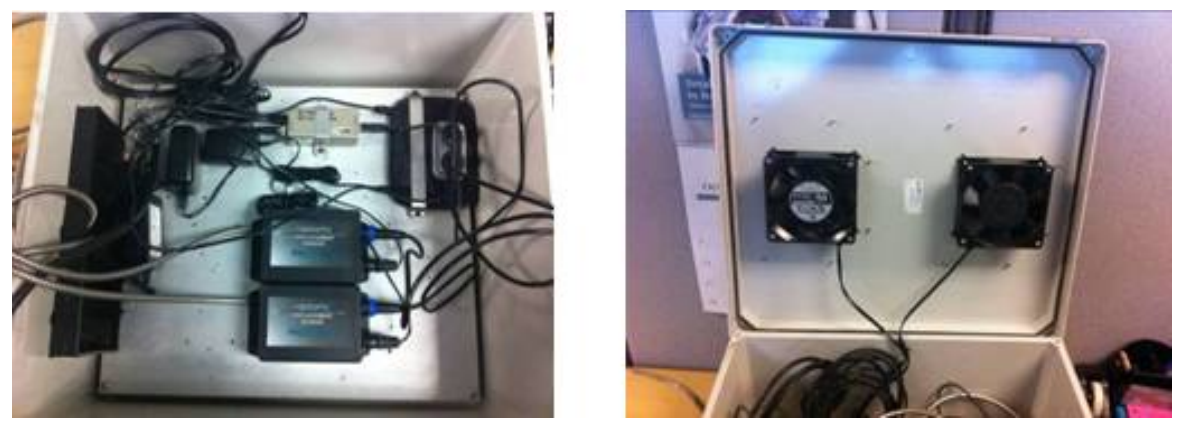

Figure 39: Electro-Optics Enclosure with Cooling Fans

\subsubsection{Sensor Calibration}

PHILTEC calibrates gap sensors on a translation stage in open space using two types of targets with different reflectivity. To achieve the specified accuracy of the distance measurement, a 50-point calibration table is saved for each sensor. This table is used to calculate the gap size. To measure the effect of the quartz spacer on the calibration we manufactured five spacers with thickness between 2.7 and $12 \mathrm{~mm}$. Figure 40 shows calibration data taken with and without the wear spacer. As might be expected, the parameter values for small distances ( $8 \mathrm{~mm}$ and smaller) are similar for air and quartz. At larger distances, reflections from the sidewalls of the plug add optical power to the receiving channels and distort the ratio. The observed ambiguity is a challenge to developing a robust calibration. This ambiguity needs to be resolved in the engine using knowledge of the installation part thickness.

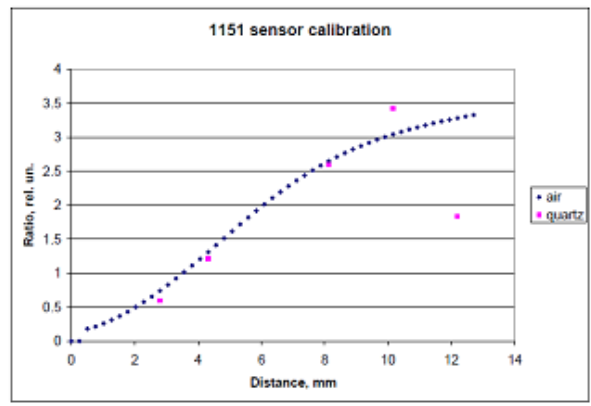

Figure 40: Calibration with and without Wear Spacer 


\subsection{Failure Mode and Effects Analysis}

Before considering installation in an engine, all risks and potential consequences have to be evaluated. We performed a formal failure mode and effects analysis (FMEA), identifying and classifying potential failure modes by their severity and likelihood.

Table 4 summarizes the results. The most likely failure in the installation was that the sensor would not be located at a position where wear would occur. This was acceptable, since the test would still obtain all the needed data on the sensor's performance, but it would not show the wear progression if none occurred We identified that there was a moderate risk that the sensor would liberated from the seal since engine vibrations can cause the threaded sensor section to loosen. A liberated sensor part could plug basket swirlers and cause considerable damage. The risk is mitigated, however, by the use of additional securing fasteners and the fact that the sensor cable is secured to hold the sensor. Other risks were of lesser consequences, and they are mitigated by applying good engineering design practices. For example, it was decided to weld the optical wear plug onto the transition seal and to double-attach the probe part onto the seal to avoid foreign object damage. The optical cable will be routed in steal tubing and spot-welded via best practice to avoid dislodging. The possibility of liberated parts plugging the combustor airflow is minimized by jacketing the cable and applying redundant probe attachment techniques.

Table 4: Summary of FMEA Results

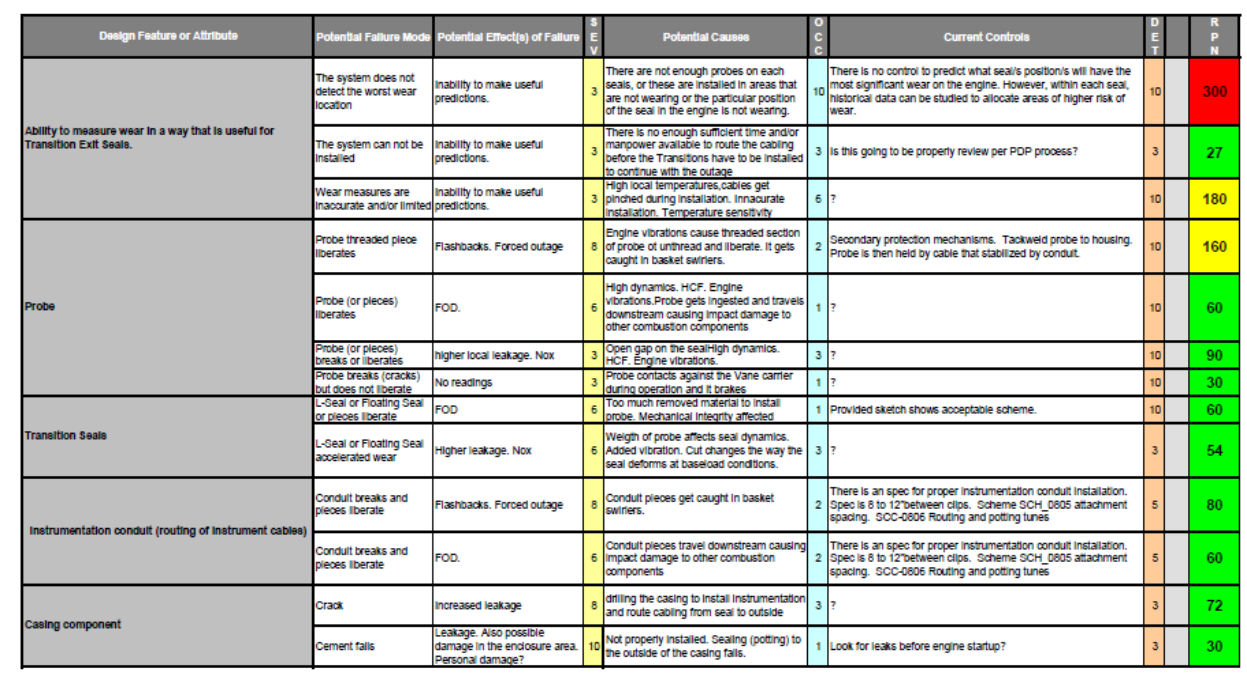




\subsection{Sensor Installation}

According to the plan, we installed two optical wear sensors at the transition floating seal of an F-Class gas turbine Figure 41 shows a photo with both sensors installed in the upper portion of the two-part seal. The optical fibers are protected by interlocking stainless steel sheathing, routed through the row 1 blade carrier.

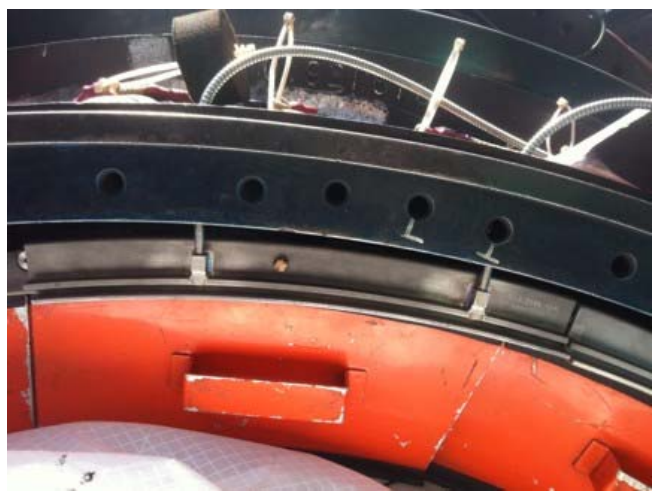

Figure 41: Wear Sensors Installed on Upper Transition Seal

Figure 42 presents a detailed look at the optical plugs after they have been spot welded to the seal. Also visible are the threaded tips of the PHILTEC fiber probes. As described earlier, these displacement sensors are rated for temperatures up to $800^{\circ} \mathrm{C}$. Inside of the stainless steel sleeves, three fiber bundles are loosely routed to the electro-optic interrogation unit of the sensor. At the very tip of the sensor, the fibers are cemented with ceramic epoxy into a zirconia ferrule resulting in a solid sensor end.

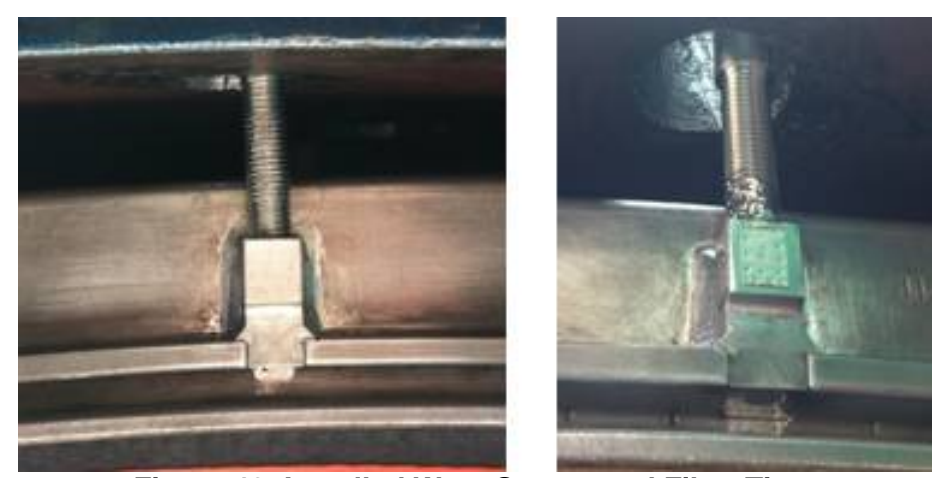

Figure 42: Installed Wear Spacer and Fiber Tip 


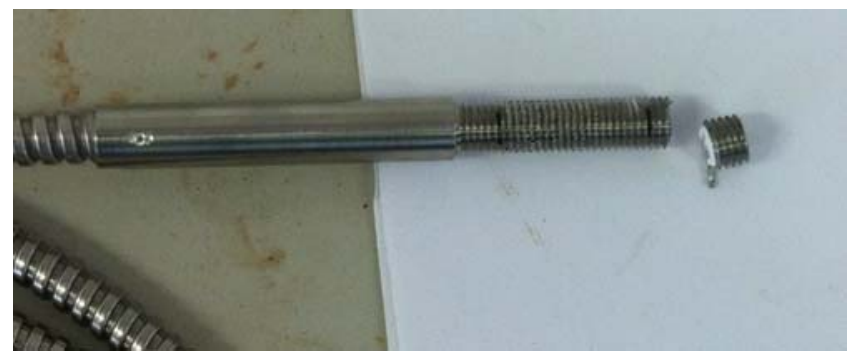

Figure 43: Broken Fiber Optic Tip

We noted that the sensor tips can be damaged rather easily. Figure 43 shows a photograph of a damaged fiber probe. The solid tip that contains the ceramic epoxy and the white zirconia ferrule simply broke off. We had to remove this sensor cable from the turbine and replace it with a spare part. Unfortunately, the only available replacement fiber was slightly shorter than the original, so we had to install the electro-optics box that contains the sensor interrogation units, power supplies, and USB-Ethernet converters closer to the turbine than originally planned.

Figure 49 shows a view of the outside of the vane carrier and the two high temperature cables as they are routed out of the transition seal area. Care was taken to keep any bend radius well above the manufacturer specified value. All fibers are fixed using clamps and spot welding. As the fiber cables are routed towards the inner wall of the turbine casing, they have to cross a gap that allows for thermal expansion of the vane carrier and outer turbine casing. Since movement of the turbine parts in that region may potentially lead to strain on the optical fiber, special installation design is needed as shown in Figure 45.

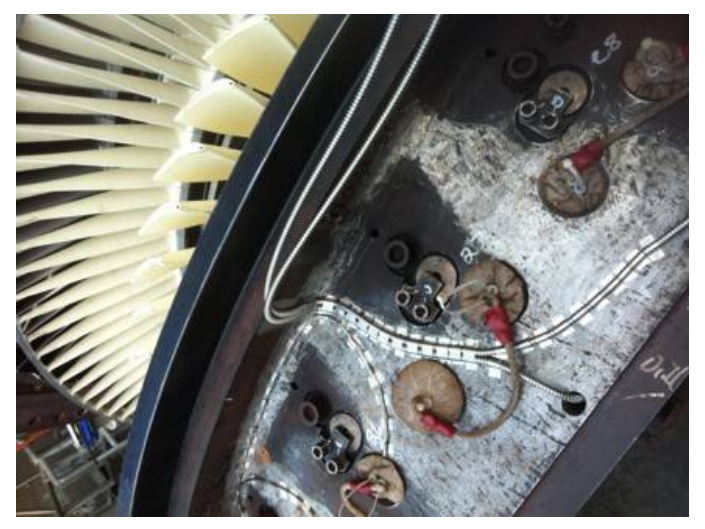

Figure 44: Row 1 Vane Carrier Showing Fiber Routing 


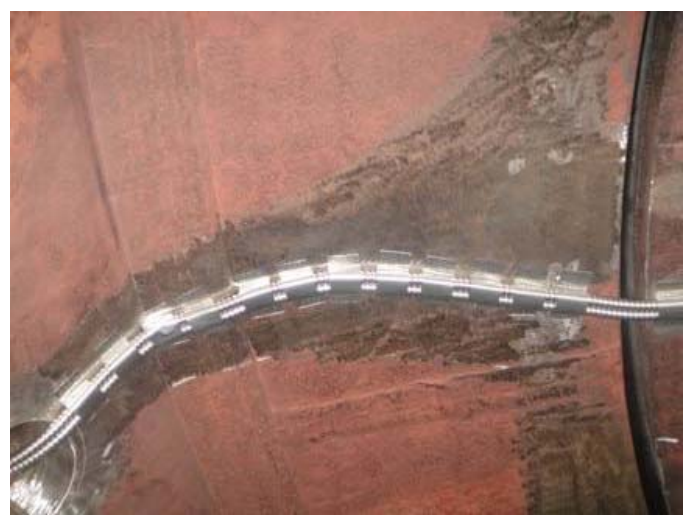

Figure 45: Fiber Crossing from Vane Carrier to Outer Turbine Casing 


\subsection{Engine Data Analysis and Discussion}

Data acquisition was done from a mobile office trailer next to the turbine housing. The software provided by PHILTEC records the raw optical signals and calculates the thickness of the wear spacer based on the calibration. The update rate between data points can be varied between $100 \mathrm{~ms}$ and 30 minutes.

\subsubsection{Initial Data at Turning Gear}

The first data from the engine were recorded on April 19, 2012. As described earlier, each fiber tip is connected to two photodetectors. One photo diode gets light from the probe area that is not used to illuminate the target. This is the "adjacent signal" originating from the probe area adjacent to the illuminated area. The second detector is connected to the reference signal from fibers intermixed with the illuminated transmit fiber. Thickness measurements are directly related to the ratio between these two signals.

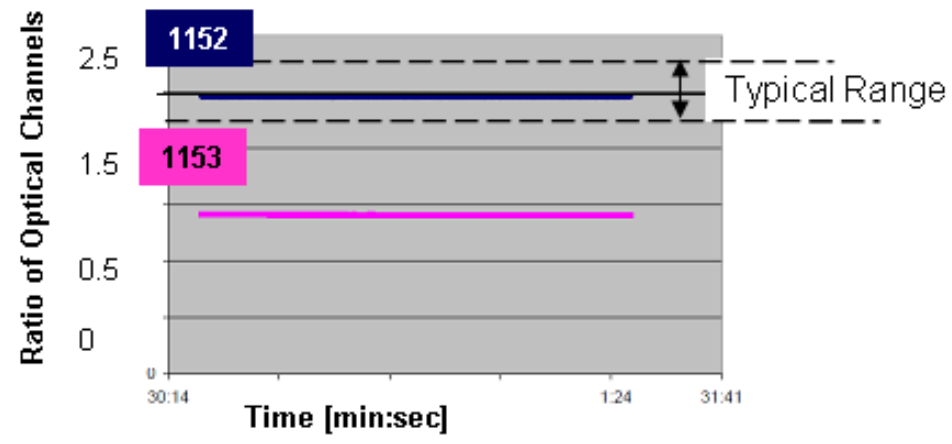

Figure 46: Ratio of the Optical Channels after Installation

Figure 46 shows the ratio of the two signals for both sensors. The typical range for this ratio is between 1.7 and 2.5, and that is confirmed in lab tests for many different sensor configurations. Although the measured ratio is well within this norm for sensor 1152, it falls out of the typical range for sensor 1153. A closer look reveals that this is caused by an unusually high intensity in the reference channel and not by signal loss. All raw signals are in target range of about 500,000 to $1,000,000$ counts. We are not sure why this ratio was low in sensor 1153 from the beginning of the engine test, but post inspection shows this sensor had several defects.

The final thickness calibration needs to be adjusted to the engine installation and a "hot calibration" was performed assuming the known plug thickness of $12 \mathrm{~mm}$. Figure 47 shows thickness measurements that were taken when the engine was running at turning gear. 
Data are shown for both sensors for a one-minute period. Data appear to be stable, and the measurement noise is on the order of a few micrometers. The graph shows data taken within one week; the measured thickness varies by less than $70 \mu \mathrm{m}$. The small drift seen in the early data of sensor 1153 completely stabilized after one week.
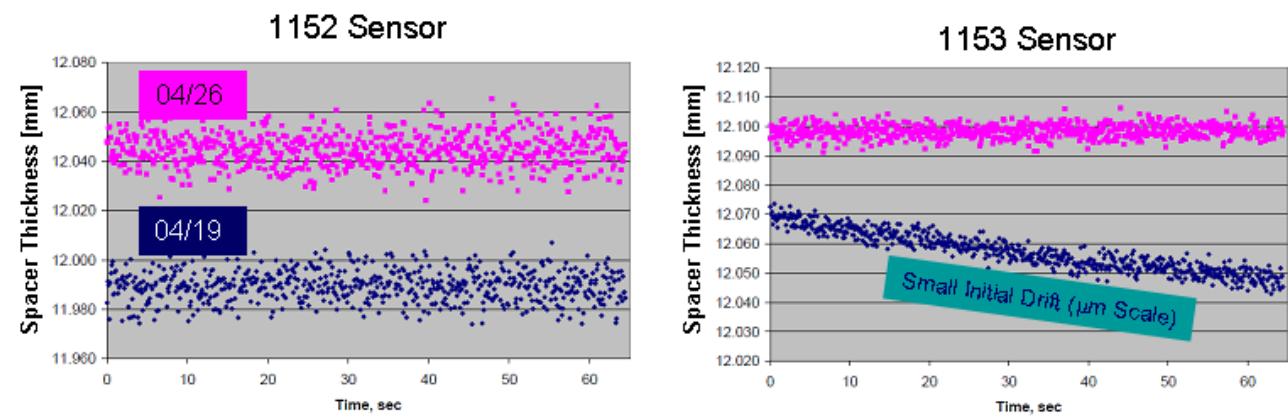

Figure 47: Thickness Measurements at Turning Gear

\subsubsection{Sensor Data at First Engine Startup to Full Load}

Figure 48 shows the optical signals in the Adjacent and Reference channel during the fist startup of the engine to full load. Data are shown for a period of 1.7 hours. All optical signals increase considerably when the engine started. This is explained by the temperature increase and the thermal expansion in the engine that leads to all gaps closing. From this point on, the transition seal is considered "loaded" meaning that both parts of the seal have solid contact. Vibration is the main cause that results in rubbing of the two parts, and this is the main cause of transition seal wear. Apart from the signal increase at startup, we find that all four signals change synchronously. Strong transients and oscillations observed here are typical for this period of initial thermalization.
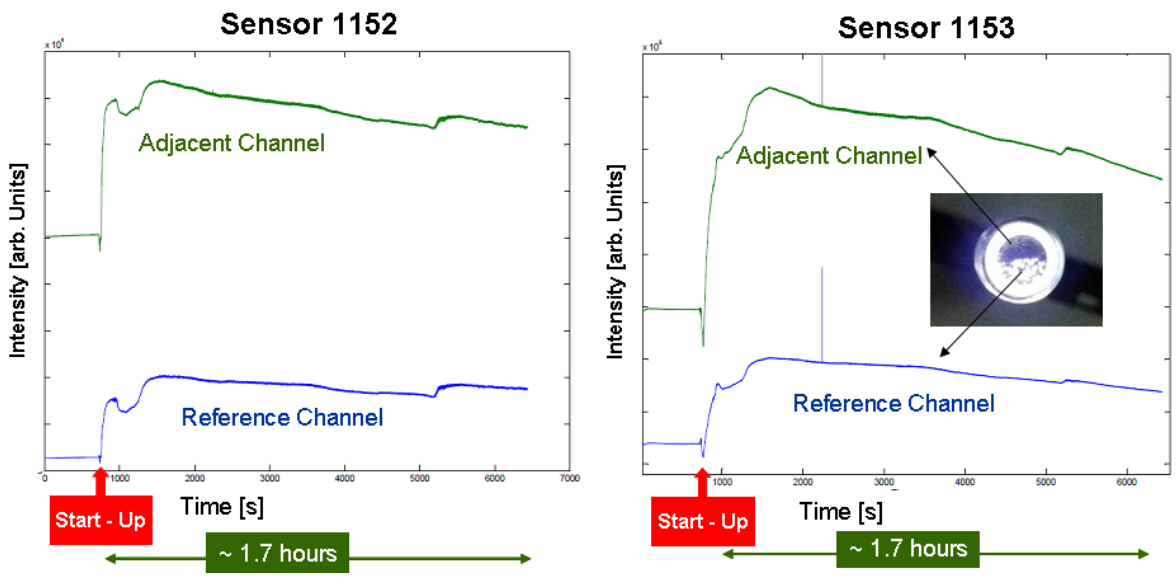

Figure 48: Wear Sensor Optical Signals at First Startup to Full Load 
Figure 49 displays the thickness data calculated from the calibration performed in the engine. We observe large changes in the recorded thickness, on the order of several millimeters, and this change is not consistent between the two sensors. Wear is not expected to take place on such a fast timescale, so we conclude that thickness measurements taken during the startup, a time of strong transient optical signals, cannot be related to wear.

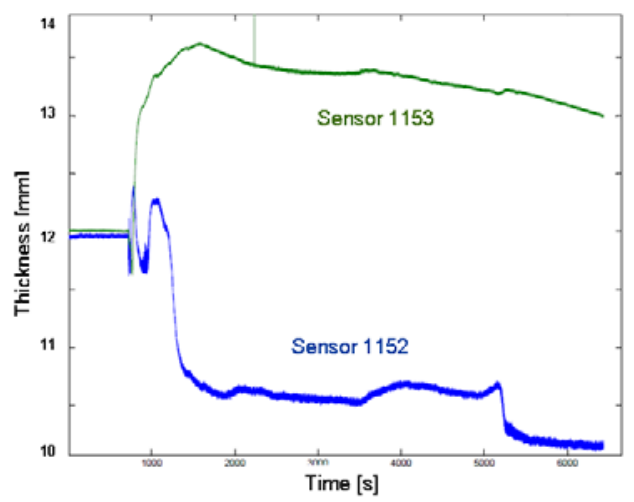

Figure 49: Spacer Thickness Measurements

\subsubsection{Optical Wear Sensor Signals over Six Months}

Figure 50 shows the optical signal intensities as a function of time for a period of more than 6 months. All signals experience a slow and steady drop during the first few days. Unfortunately, we experienced a data acquisition problem and lost some data. Within 100 hours of operation, all optical intensities dropped by almost two orders of magnitude. At this point, the signals intensities are low enough that they are close to the noise limit.

On October 5, 2012, the potting used to seal the egress tube guiding the fiber optic cables outside of the turbine casing failed. The high temperature optical cables were torn, so all measurements were disrupted. During our pre-installation risk assessment analysis, we anticipated this failure mode. Using procedures developed for other sensor installations however we expected, this risk to be low. An issue was found in the potting procedure applied to sensor's casing exit port that caused the failure. 


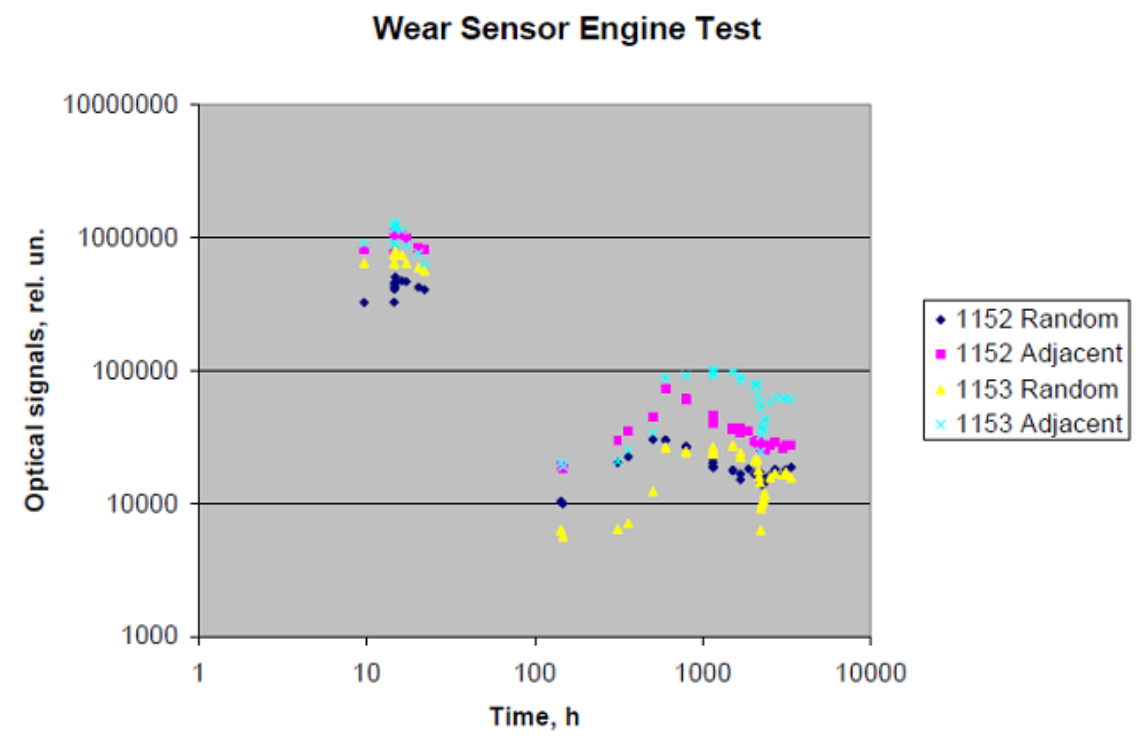

Figure 50: Optical Signal Intensities Over 6 Months

\subsection{Post Installation Inspection and Findings}

The sensor was disassembled at an outage. Post inspection reveals that the sensor wore with the rubbing parts, as designed, but the optical cables and spacer design need to be improved. While the inner silica surfaces of the silica spacers seem contaminated, but largely intact, we observe thermal damage and cracks on the outside, in particular for sensor 1153. From visual inspection, it seems likely that this sensor experienced higher temperatures during the engine installation. This is consistent with the heavy damage found on the fiber tip of 1153 and the fact that very little is remaining of the optical fiber cable. Some round edges in the fiber pieces even indicate softening of the silica fiber during engine operation.

\subsubsection{State of the Optical Wear Spacers}

We inspected the transition seal after it was removed from the engine. Figure 51 shows the outer transition seal and a detailed view of the two wear spacers 1152 and 1153 . 


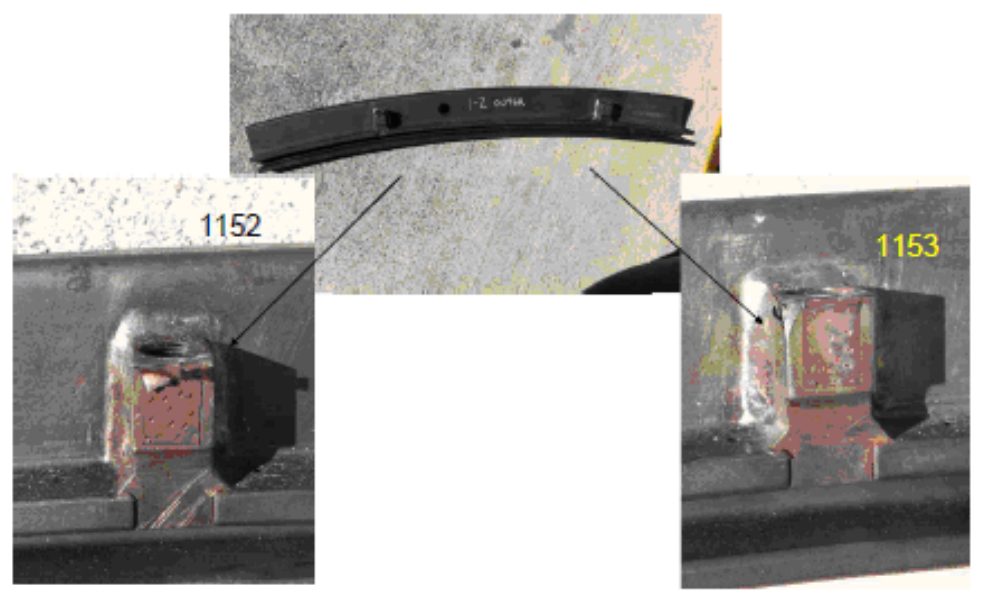

Figure 51: Wear Sensors Spacers Post Inspection

Both wear spacer assemblies show clear sign of mechanical abrasion and wear. Figure 52 shows photographs of both sensors. Both sensors show a $0.2-0.3 \mathrm{~mm}$ deep step that is typical for the wear experienced in this engine part. The silica spacer in sensor 1153 is, however, chipped and broken.
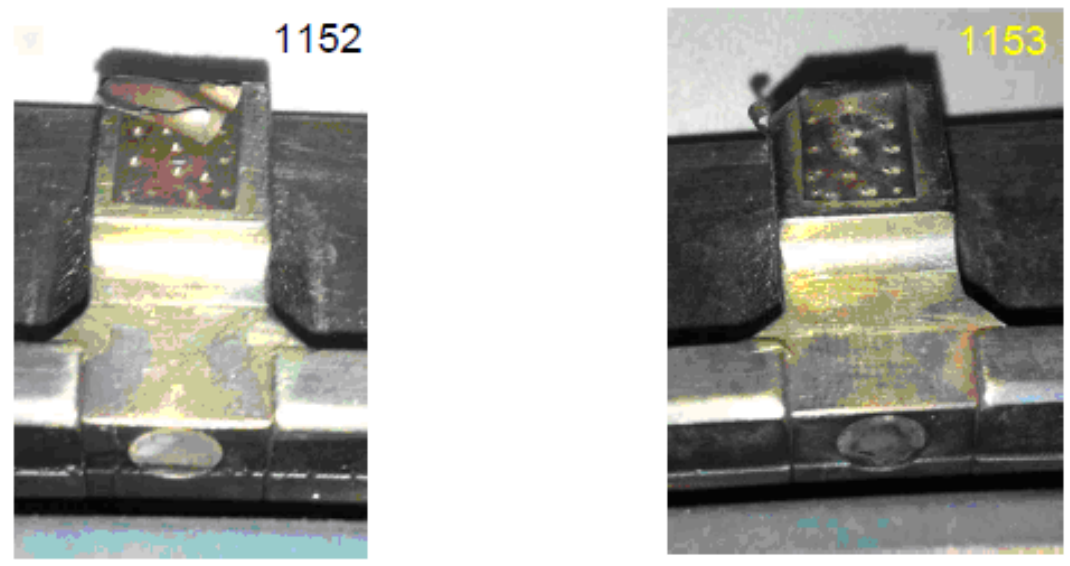

Figure 52: Wear Spacer Showing Signs of Wear

Although contaminated to some degree, both silica spacers still show transparency as seen in Figure 53. 

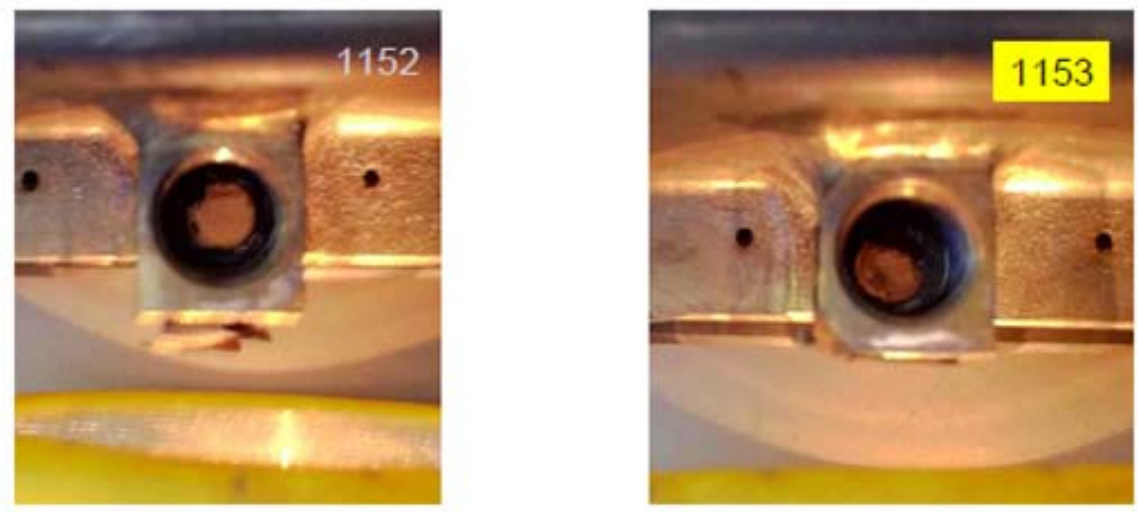

Figure 53: Wear Spacers Are Transparent Post Inspection

A simple pressure test revealed that while the seal in sensor 1152 is still intact, it was broken in sensor 1153 .

| Figure 54, shows detailed views of the contamination found on the inner silica surfaces (fiber side) of both sensors. Clearly, sensor 1153 shows a much higher level of contamination and degradation. The silica spacer is detached from the stainless steal housing in both wear assemblies.

1152
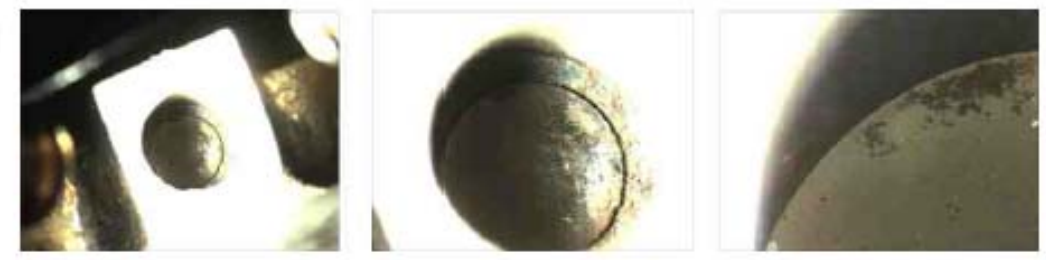

1153
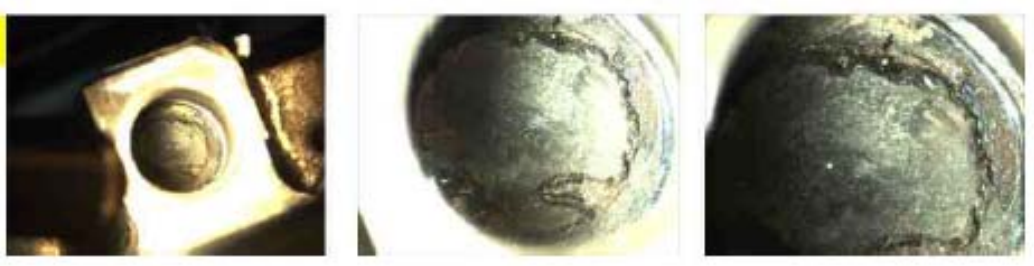

Figure 54: Contamination on Inner Spacer Surfaces 
The photographs in Figure 55 show the outer silica surfaces that were exposed to high temperature and mechanical wear. While the silica spacer in sensor 1152 is still intact, sensor 1153 shows signs of cracking and chipping that looks like a result of thermal stresses from the stainless steel housing.
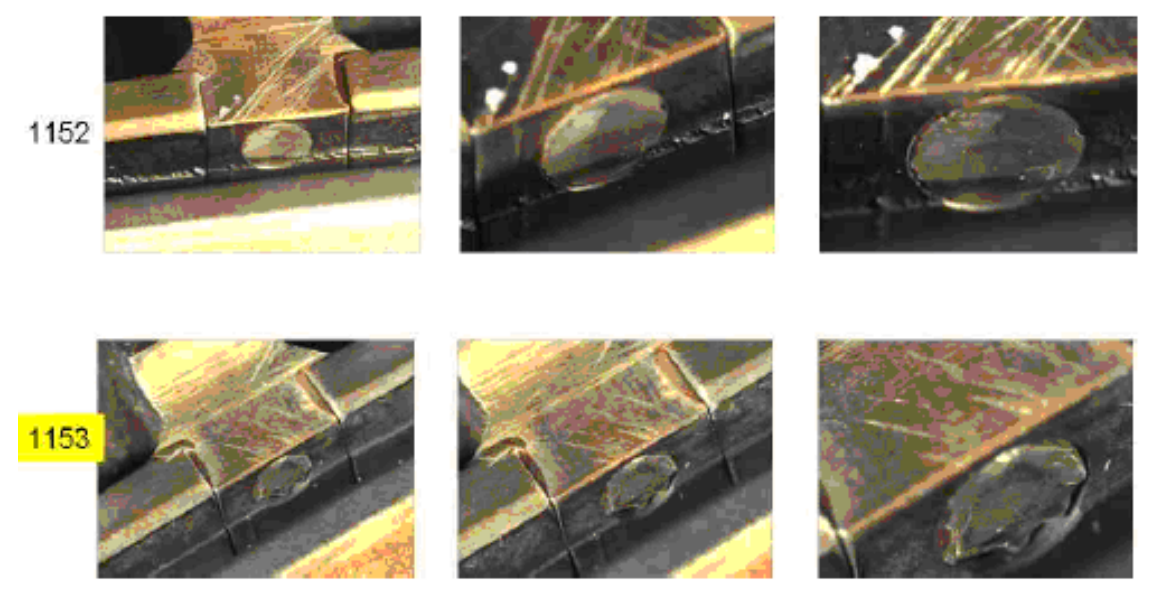

Figure 55: Illustration of Cracking in Spacer 1153

\subsubsection{Wear Found on Sensors Consistent with Transition Seal Wear}

The transition seal shows wear typical for engine operation. While the center of the seal segment shows almost no wear, both sides of the seal show a step-like groove $0.5-0.7 \mathrm{~mm}$ deep and 14 to $16 \mathrm{~cm}$ long. At the sensor positions, wear depth is about $0.2-0.3 \mathrm{~mm}$.

\subsubsection{State of the Optical Fibers}

Only short, about $15 \mathrm{~cm}$ long end pieces of the fiber assembly were available for post inspection. Figure 56 shows photographs of the recovered optical fibers tips and remaining optical fibers. Both fiber tips appear damaged with sensor 1153 again showing the higher amount of damage and degradation. A few millimeter long pieces of fiber could be extracted from sensor 1152. They appear shorter but similar to the pieces extracted from the high temperature fiber cable outside the engine. The fiber pieces extracted from sensor 1153 look like dust and are much smaller. 


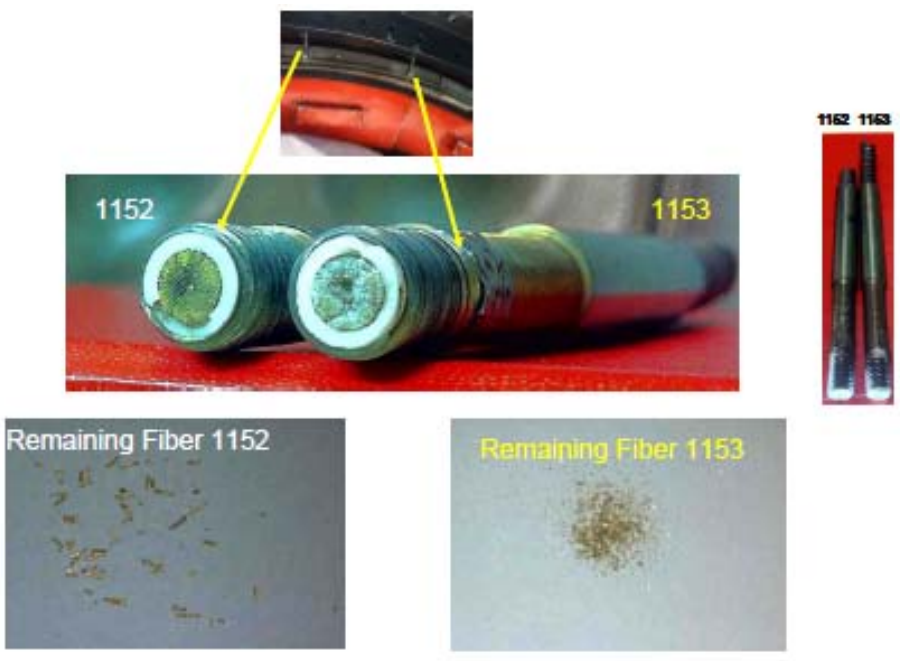

Figure 56: Fiber Tip Damage

Figure 57, shows micrographs of both fiber tips. Fiber tip 1152 shows some degree of structural integrity. Sensor tip 1153 is, however, heavily damaged and shows large voids. The large amount of missing epoxy is consistent with the higher amount of surface contamination found in that sensor 1153's wear spacer assembly.
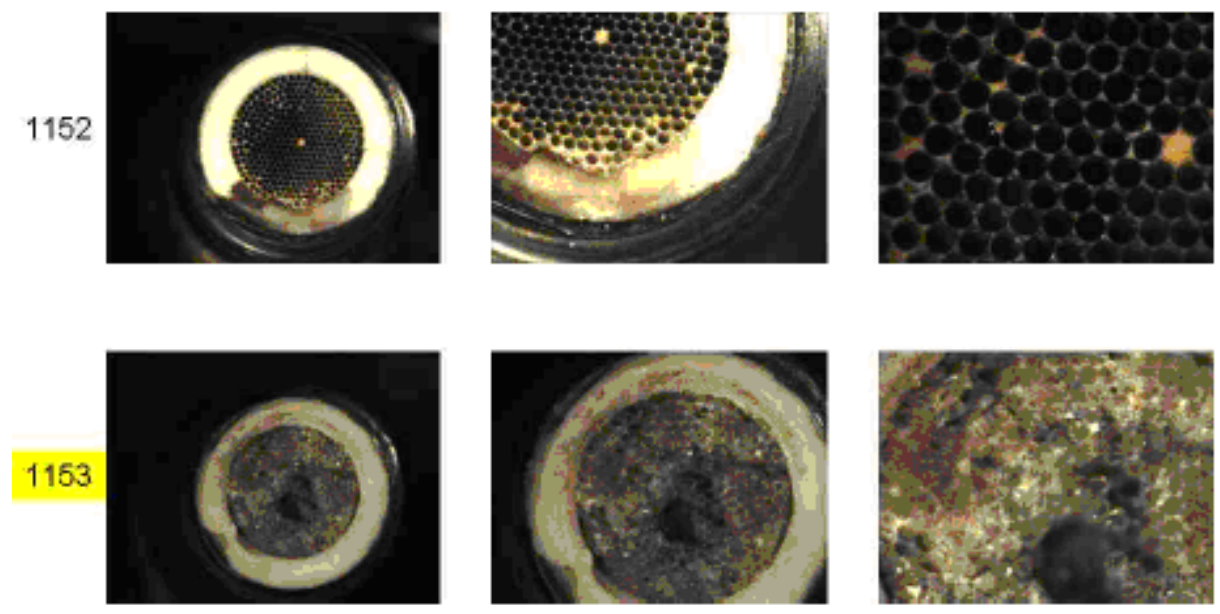

Formatted: Position: Horizontal: Left, Relative to: Column, Vertical: In line, Relative to: Margin, Horizontal: $0 \mathrm{~cm}$, Width: Auto, Wrap Around

Deleted: ๆ

Figure 57

Figure 57: Photomicrographs of Fiber Tips 
Figure 58 shows micrographs of the remaining optical fiber in both cables. All fiber pieces show a brownish discoloration. In sensor 1152, we found evidence of occasional separation of the coating from the fiber. All edges and fiber break surfaces appear sharp. Fiber 1153 has much smaller pieces remaining. Some fiber pieces show round edges.

1152
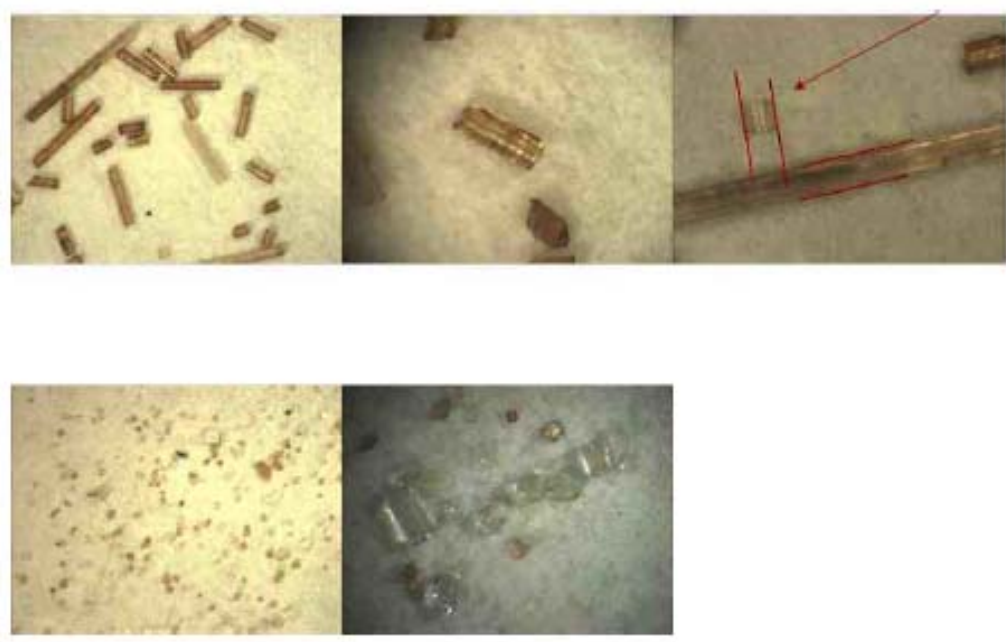

Figure 58: Photomicrographs of Fibers Post Inspection

\subsubsection{State of Electro-Optics Box}

We tested both sensor systems with a spare high temperature sensor cable and wear sensor. Since all signals were measured in the range of their initial levels of $0.5-1$ million units, so we conclude that the external electro-optics boxes were functional throughout the testing.

Although the solid fiber tips were tested to be able to withstand the high temperatures expected inside the engine $\left(\sim 700-800^{\circ} \mathrm{C}\right.$ at the transition seal), the length of fused silica high temperature fiber cable used to route the light outside the engine was not proven capable or long term operation at high temperatures. Fiber fatigue and microcracking under high temperature, humid atmospheres are typical failure modes for fused silica fiber.

PHILTEC's fiber optic gap sensors were, however, used by Siemens in different lower temperature locations inside engines with varying levels of success. Although there are many differences in these installations, the smaller diameter borosilicate fiber cables used in standard fiber bundle assemblies seem to work better in engine applications inside the casing than the high temperature fused silica fiber cable selected for the wear sensor installation. Two installations used this borosilicate fiber cable. In both cases, the fiber was still structurally intact after five months of operation. Although the borosilicate fiber has a lower softening point, it is far less brittle (a soft glass), so it seems to better withstand the engine environment, especially if operating conditions are less than $350^{\circ} \mathrm{C}$. 


\section{Conclusions}

On-line monitoring to support condition based monitoring of gas turbine combustion components requires the development of intrusive sensors that can reliably and accurately monitor critical conditions of hot components for long durations. Not only must the sensor perform accurately under harsh conditions, but the signals generated must be transported long distances while maintaining signal integrity. This project shows the access and egress wiring of the sensors were the limiting factors for both sensor types developed. To achieve a successful application, the sensing method has to be designed to function correctly in an engine and the sensors must function and survive high temperature, vibratory engine environments. In addition, the sensor's electrical or optical signals must be transmitted for meters from the measurement point to the electronic processing equipment. The sensor transmission cabling must be robust to temperature and vibration. Signal transmission must also be robust for long distances. Finally, the attachment of the signal transmission cabling to the sensor at the high temperature measurement point must be reliable.

A magnetic crack detection sensor was developed that functioned with short transmission cables. Signal distortion with distance and the ability to robustly attach cabling to the sensor, however, proved the limiting factors to this crack sensor's success.

An optical wear sensor proved to measure the wear in lab tests, and it functioned in an engine environment. The optical method has potential to measure wear with uncertainties of less than $0.3 \mathrm{~mm}$ at high temperatures $\left(800^{\circ} \mathrm{C}\right)$ on mated parts. The sensor probe, method, and electronics proved viable in lab and engine tests. The optical transmission cable and the optical spacer, however, proved to be the life-limiting factors for the sensor's engine use. 